\title{
Stores, Channels, Glue, and Trees: Active Glial and Active Dendritic Physiology
}

\author{
Sufyan Ashhad ${ }^{1} \cdot$ Rishikesh Narayanan $^{2}$ (D)
}

Received: 24 November 2017 / Accepted: 3 July 2018 / Published online: 16 July 2018

(C) The Author(s) 2018

\begin{abstract}
Glial cells and neuronal dendrites were historically assumed to be passive structures that play only supportive physiological roles, with no active contribution to information processing in the central nervous system. Research spanning the past few decades has clearly established this assumption to be far from physiological realities. Whereas the discovery of active channel conductances and their localized plasticity was the turning point for dendritic structures, the demonstration that glial cells release transmitter molecules and communicate across the neuroglia syncytium through calcium wave propagation constituted path-breaking discoveries for glial cell physiology. An additional commonality between these two structures is the ability of calcium stores within their endoplasmic reticulum (ER) to support active propagation of calcium waves, which play crucial roles in the spatiotemporal integration of information within and across cells. Although there have been several demonstrations of regulatory roles of glial cells and dendritic structures in achieving common physiological goals such as information propagation and adaptability through plasticity, studies assessing physiological interactions between these two active structures have been few and far. This lacuna is especially striking given the strong connectivity that is known to exist between these two structures through several complex and tightly intercoupled mechanisms that also recruit their respective ER structures. In this review, we present brief overviews of the parallel literatures on active dendrites and active glial physiology and make a strong case for future studies to directly assess the strong interactions between these two structures in regulating physiology and pathophysiology of the brain.
\end{abstract}

Keywords Endoplasmic reticulum · Ion channels $\cdot$ Astrocytes $\cdot$ Active dendrites $\cdot$ Gliotransmission

\section{Introduction}

The role of glial cells and neuronal dendrites, especially involving the multifarious interactions among them, in active information processing in the central nervous system (CNS) has not been fully understood. Glial cells and neuronal dendrites share many commonalities ranging from the integral membrane components (receptors and ion channels) to the presence of endoplasmic reticulum (ER) as a calcium store and the elaborate molecular machinery that sustains active propagation of calcium signals across these structures. Historically, both glial cells and dendritic structures were thought to be passive structures that are not actively involved

Rishikesh Narayanan

rishi@iisc.ac.in

1 Department of Neurobiology, University of California at Los Angeles, Los Angeles, CA 90095, USA

2 Cellular Neurophysiology Laboratory, Molecular Biophysics Unit, Indian Institute of Science, Bangalore 560012, India in information processing. Although decades of research have clearly demonstrated the active nature of glial and dendritic structures and have shown their critical roles in information processing, the potential of how their interactions could contribute to brain functions has not been fully explored. In this review, we discuss various aspects of active physiology and active calcium signal propagation in neuronal dendrites and glia. We present the similarities and differences between glial and dendritic structures, cataloging the impact of interactions between neurons and glia in achieving convergent physiological goals. Importantly, we emphasize the need to systematically study direct interactions between active dendritic and active glial signaling and contend that such interactions and plasticity therein are vital components in encoding, storage, processing, and propagation of information in the CNS.

In the sections below, we first individually introduce calcium stores, glial cells, and active dendrites, also briefly introducing the active nature of signaling through the presence of voltage- and/or calcium-dependent channels and receptors in the plasma membrane and the ER membrane of glial and dendritic structures. Next, we categorize different types of 
interactions spanning the ER and the plasma membranes of dendrites and glia, outlining the importance of each type of interaction to several aspects of brain physiology. Finally, we present potential future directions for where research on intracellular and intercellular interactions spanning these active structures could be directed towards, also emphasizing the need to systematically assess activity-dependent plasticity in such interactions.

\section{The Components: Active Glia, Active Dendrites, and Their Endoplasmic Reticulum}

Calcium stores in the ER are essential components for calcium signaling across various cell types in the eukaryotes [1-3]. Release of calcium from these stores, through inositol trisphosphate receptors ( $\mathrm{InsP}_{3} \mathrm{Rs}$ ) and ryanodine receptors (RyRs) expressed on the ER membrane, has been shown to regulate a myriad of physiological and pathophysiological processes in neurons and glia [1, 2, 4-12]. Neuronal ER calcium release plays crucial roles in mediating short- and longterm plasticity and in sustaining actively propagated waves of calcium within and across cells [10, 13-20]. Furthermore, release of calcium from the ER store forms the principal source of cytosolic calcium elevations in the glial cells. Such release of store calcium through $\mathrm{InsP}_{3} \mathrm{Rs}$ in astrocytes enables them to respond to local network cues also through calcium waves. These waves can either be localized within a single cell or travel as intercellular waves propagating into multiple astrocytes that comprises the astrocytic syncytium. Elevations in the cytosolic calcium concentration lead to the release of neuroactive substances from the glial cells which can bind to and activate neuronal receptors, a process termed as gliotransmission [21-29]. These observations about active glial signaling have significantly furthered our understanding of these cells, beyond earlier assumptions that these cells are passive and behave merely as the "glue" that structurally binds neural tissue (the word glia is derived from the Greek word for glue). Together, ER stores in these cell types serve as critical substrates for the integration and transfer of information through the network of neurons and glia across the CNS $[8,11,12,22,24,27,30-36]$.

The functional roles of neuronal dendrites, the elaborate and morphologically complex structures that emanate from the somata, have intrigued neuroscientists for over a century. Classically, neuronal dendrites were also assumed to be passive structures acting as the "receptive apparatus" that funnel the synaptic potentials towards the soma [37-43]. However, the advancements of electrophysiological and imaging techniques have made these fine caliber structures tractable, yielding experimental observations where specific physiologically relevant signals can be directly recorded from these dendritic structures [44-53]. These technological advancements have led to an explosion of information about neuronal dendrites and it is now established that the dendritic plasma membranes express a plethora of voltage-gated ion channels (VGICs). Remarkably, several of these VGICs are expressed heavily in the dendrites with higher densities than at the soma [43, 54-59].

Voltage-gated ion channels in dendritic structures mediate active backpropagation of action potentials [45, 54, 60] and bestow upon dendrites the ability to initiate local dendritic spikes that act as dendritic outputs [61-68]. In addition, these active components in dendritic structures are critical regulators of location-dependent feature selectivity, spike phase coherence, signal integration, and coincidence detection in neurons [51, 54, 58, 66, 69-88]. Importantly, as the structural substrate for most synaptic receptors, channels, and other transmembrane proteins, dendrites are also critically involved in the plasticity of all these components which contribute to the adaptability of neuronal structures to afferent inputs [38, 43, 70, 89-97]. The discovery of plastic active dendrites has resulted in a paradigm shift in our understanding about neuronal information processing, whereby it is now clear that neuronal dendrites play a dominant role in signal integration, neural computation, plasticity, and associated adaptibility in neuronal structures.

Contiguous to the plasma membranes of neurons (extending to dendrites, spines, axons, and boutons) and astrocytes (extending across its processes) runs the ER that forms a continuous membranous network throughout the cytoplasm [1, $10,98,99]$. The cellular rules governing the resting concentrations of calcium in the cytosol and the ER lumen are in stark contrast to each other. Whereas the resting levels of cytosolic calcium are in the nanomolar range, it is in the high micromolar to low millimolar ranges within the ER lumen $[1,10,11$, 100, 101]. Thus, the ER calcium can be released into the cytosol by activation of either RyRs or $\mathrm{InsP}_{3} \mathrm{Rs}$ which have calcium and $\mathrm{InsP}_{3}$ as their endogenous ligands, respectively. There are three isoforms of $\mathrm{InsP}_{3} \mathrm{Rs}$, with the $\mathrm{Ins}_{3} \mathrm{R} 1$ acting as the principal neuronal subtype and the $\mathrm{Ins}_{3} \mathrm{R} 2$ primarily expressed in the astrocytes [102-106]. Upon appropriate stimulation, these receptors open and release calcium into the cytosol which can have varying spatiotemporal dynamics depending upon the strength of the stimulation.

A unique feature of both the $\operatorname{Ins}_{3} \mathrm{Rs}$ and the RyRs is their bell-shaped dependence on cytosolic calcium levels, with lower cytosolic calcium concentration $\left(\left[\mathrm{Ca}^{2+}\right]_{\mathrm{c}}\right)$ acting as a coactivator and higher $\left[\mathrm{Ca}^{2+}\right]_{\mathrm{c}}$ acting as an inhibitor for both of these receptor classes. Thus, at moderate increase in $\left[\mathrm{Ca}^{2+}\right]_{\mathrm{c}}$, binding of calcium to InsP $\mathrm{P}_{3} \mathrm{Rs}$, along with $\mathrm{InsP}_{3}$, amplifies $\left[\mathrm{Ca}^{2+}\right]_{\mathrm{c}}$ increase by enhancing the flux of calcium through the Ins $_{3} \mathrm{Rs}$ whereas higher $\left[\mathrm{Ca}^{2+}\right]_{\mathrm{c}}$ results in inhibition of these channels even in the presence of $\operatorname{InsP}_{3}[105$, 107-110]. This dependence of the ER calcium release channels on $\left[\mathrm{Ca}^{2+}\right]_{c}$ also results in varied spatiotemporal 
characteristics of the ER calcium signaling. For instance, consequent to a relatively weak stimulus and localized mobilization of $\operatorname{InsP}_{3}$ within the cytosol, a small number of $\operatorname{InsP}_{3} \mathrm{Rs}$ are activated leading to localized calcium elevation constituting a calcium microdomain - also known as a calcium spark [3]. In contrast, a strong stimulus can lead to a widespread mobilization of $\mathrm{InsP}_{3}$ which thus recruits a higher number of $\mathrm{InsP}_{3} \mathrm{Rs}$ on the ER membrane. The calcium dependence of $\mathrm{InsP}_{3}$ receptors is dependent on several factors, including the specific subtype of $\operatorname{Ins}_{3} \mathrm{R}$ and their interactions with other signaling components such as cytochrome C $[105,107,111-113]$.

Calcium released through these receptors can further diffuse to the nearby receptors at high enough concentrations to synergistically increase the flux of calcium which results in regenerative release of calcium from the ER stores - a mechanism referred to as calcium-induced calcium release (CICR). Through the recruitment of such processes, large amplitude regenerative release of calcium can actively propagate as calcium waves over long distances within a cell. This acts to synchronize and integrate signal processing across various neuronal compartments and is an essential element of biochemical signal processing. The calcium waves can also cross over to the neighboring cells which are connected through gap junctions and by the process of CICR constitute intercellular waves that are prevalent across the glial syncytium $[2-5,10,16,19,107,114-121]$.

As the scope of this review is on the interactions between active glia and active dendrites, including interactions with the ER membrane within both structures, we refer to reviews on active dendrites [38, 39, 42, 43, 81, 93, 122], gliotransmission $[8,21,22,24,26-28,123-125]$, and ER signaling in neurons and glia $[1-4,6,7,10-12,19]$ for further details on each of these individual components. In what follows, we assess interactions across these components and associated plasticity mechanisms.

\section{Trees and Stores: Active Dendrites and ER Membrane}

Several neuronal subtypes across the brain are endowed with extensive dendritic arborization. In pyramidal neurons of the cortex and the hippocampus, the neuronal architecture is such that several thin caliber oblique dendrites form branches of a main apical dendritic trunk, with several basal dendrites emanating from the cell body [126-129]. On their plasma membrane are present several VGICs with varying biophysical properties and subcellular distributions [38, 43, 56, 57, 93, 130]. Parallel to the neuronal plasma membrane is the ER membrane that forms a continuous network throughout the neuronal morphology. Upon activation of specific metabotropic receptors or elevation of cytosolic calcium through other sources, the Ins $\mathrm{P}_{3} \mathrm{Rs}$ and RyRs present on the ER membrane respond by releasing calcium into the cytosol, which can exhibit diverse dynamics depending upon the strength of stimulation $[3,16$, $19,47,48,114-116,120,131]$. Such a structure constitutes two parallel active membranes (the ER and the plasma membrane), which are endowed with channels, receptors, pumps, and other transmembrane components, that participate in active propagation and integration of information across the neuronal structure.

In addition to the structural contiguity of the ER and the plasma membranes in neuronal structures, there are profound functional similarities with reference to signal propagation across these two membranes [132]. Whereas the neuronal plasma membrane with its channels, receptors, and pumps mediates the electrical signal propagation, the ER membrane and its receptors participate in the calcium signal propagation along the dendritic length. A main source of excitatory electrical potentials in the dendrites is sodium entry through ionotropic synaptic receptors which leads to membrane depolarization that propagates towards the soma. The spatiotemporal spread of such signals is determined by the extent of dendritic filtering based on the passive and active properties of the dendritic compartments. Under a purely passive propagation, the magnitude of decay in such synaptic potentials is determined by the electrotonic length constant $\left(\lambda_{E}\right)$ of the dendrites [133]. $\lambda$ denotes the distance at which a propagating signal attenuates to $37 \%$ of its initial amplitude. For a neurite with the same set of passive parameters, a time-varying signal (such as excitatory post synaptic potentials, EPSPs, and action potentials, AP) undergoes heavier attenuation compared to a steady state signal. Thus, the length constant for the voltage signal obtained in response to a direct current injection $\left(\lambda_{\mathrm{DC}}\right)$ is greater than the length constant with reference to a time-varying signal $\left(\lambda_{\mathrm{AC}}\right)$. Furthermore, the faster the kinetics of a timevarying signal, the higher is its attenuation as it propagates passively, implying that an action potential would attenuate much more than an EPSP for the same distance on the same cable [133].

Although this is the scenario under passive propagation, under physiologically realistic conditions, a synaptic potential is subjected to modifications by both passive as well as active properties of the dendrites. This is effectuated through ornate spatiokinetic interactions between the propagating potential and various VGICs [38, 54, 73, 91, 93, 134-140]. Generation of AP that constitutes an active regenerative signal propagation involves a positive feedback loop where a small amount of depolarization leads to further opening of the fast sodium $(\mathrm{NaF})$ channels thereby leading to more depolarization of the membrane, ultimately giving rise to a fast deflection in membrane voltage. Following the voltage-dependent activation, conformational changes in $\mathrm{NaF}$ channels result in their inactivation such that the inactivation is indirectly voltage-dependent. Subsequent voltage-dependent activation of high threshold delayed rectifier $\mathrm{K}^{+}$channels completes the repolarization of the membrane. Thus, the AP wave propagates through voltage depolarization of the membrane [134, 141-145]. 
The ER membrane can also participate in the passive and active calcium-based signal propagation. Analogous to the attenuating passive propagation of electrical potentials, a relatively small flux of calcium through the ER receptors or voltage-gated calcium channels leads to passive diffusion of calcium to nearby locations. The extent of such diffusion is determined by the diffusion coefficient of calcium ion in the cytosol, binding to calcium buffers and several "off" mechanisms that result in the extrusion of calcium from the cytosol $[3,120,146]$. The attenuation in the calcium signal can be quantified by a space constant for calcium decay within the cytosol, denoted by $\lambda_{\mathrm{Ca}}$. Notably, elaborate cellular calcium handling mechanisms lead to stringent control of cytosolic calcium elevations, thereby causing $\lambda_{\mathrm{Ca}}$ to be smaller than $\lambda_{\mathrm{E}}[132,147]$. This reflects compartmentalization of the downstream signaling pathways that the elevated calcium elicits and is crucial for establishing micro- and nanodomains of calcium signaling [3, 120, 146, 148, 149]. During active calcium signal propagation, CICR-dependent amplification of the ER calcium release constitutes a positive feedback loop resulting in large elevations in the cytosolic calcium. This steep rise in the cytosolic calcium then acts as an inhibitor for the ER receptors (due to the bell-shaped dependence of the Ins $\mathrm{P}_{3} \mathrm{Rs}$ and RyRs on the cytosolic calcium), thereby shutting the flux of calcium from the ER. Thus, the active propagation of calcium signal encompasses regenerative release of calcium from the ER stores that propagates in the form of calcium waves [2, 3, 19, 105, 107, 146].

Although there are significant qualitative equivalences in active and passive signal propagation across the active dendritic plasma membrane and the active ER membrane, there are several quantitative differences in terms of the spatial and temporal spread of these signals and the mechanisms that govern such spread. Specifically, the calcium signals are typically slower than their electrical counterparts, although their spatial spread is much constricted compared to electrical signal spread.

\section{Waves in Trees: Parameters Governing Active Dendritic Calcium Wave Propagation}

Calcium waves have been observed in various neuronal subtypes $[3,16,19,48,120,150,151]$. They constitute large amplitude elevations in the cytosolic calcium which can rise up to a few micromolars and last for about 1-2 s. Calcium waves can be elicited by physiologically relevant synaptic stimulations as well as pharmacological agents that lead to the mobilization of cytosolic $\operatorname{Ins}_{3}$. Specifically, synchronous synaptic stimulation results in a delayed increase in the cytosolic calcium as opposed to the fast and relatively small influx of calcium through the opening of synaptic receptors and VGCCs during the stimulation. The resultant wave propagates regeneratively to a distance of several tens of microns by recruiting CICR from the nearby clusters of $\mathrm{InsP}_{3} \mathrm{Rs}$ on the ER membrane. Furthermore, when synaptic stimulation is paired with a short train of somatically induced APs, the depolarization-induced calcium influx leads to a synergistic increase in the calcium release from the ER stores. This enhances secondary elevation in the cytosolic calcium which expedites initiation and propagation of calcium waves in the apical dendritic shaft [16, 19, 115, 116, 151-154]. Mechanistically, the initial trigger for the wave initiation is provided by the activation of group I metabotropic glutamate receptors (mGluRs) and consequent mobilization of cytosolic $\mathrm{InsP}_{3}$ during synaptic stimulation [3, 4, 16, 19, 116, 155].

Synaptically activated calcium waves always initiate at the branch point of the oblique dendrite on the apical dendritic trunk closest to the stimulating electrode [115]. Furthermore, even when the synaptic stimulation is paired with somatic APs, these waves are not able to invade the soma. The low surface area to volume ratio at the soma effectively acts as a sink thereby diluting the concentrations of $\operatorname{Ins}_{3}$ and calcium that diffuse into the soma, together disrupting the regenerative flux of calcium from the ER stores [19, 115, 153, 156]. Consistently, when the calcium waves are elicited by direct infusion of $\mathrm{InsP}_{3}$ into the soma (through a patch pipette) or by bath application of mGluR1 agonist 1-aminocyclopentanetrans-1,3-dicarboxylic acid (t-ACPD), they can invade the soma [116, 152, 153]. These experiments establish that the functional $\mathrm{Ins}_{3} \mathrm{Rs}$ are indeed present at the soma of these neurons. Concordantly, immunohistochemical and electron microscopic studies have also established the presence of Ins $\mathrm{P}_{3} \mathrm{Rs}$ in neuronal soma, dendrites, and axons. Interestingly, in the CA1 pyramidal neurons the highest density of $\mathrm{Ins}_{3} \mathrm{Rs}$ is present in the somatic layer which monotonically decreases towards the distal apical dendrites [102, 104, 106, 157].

Although several structural and functional similarities exist between the ER and the plasma membranes, a largely unaddressed question is how the dendritic plasma membrane interacts with the ER membrane and its components to shape neuronal physiology (Fig. 1)? In the past decade, various kinds of interactions between the ER and the plasma membranes have been investigated that have opened new avenues towards our understanding of the ER-plasma membrane interactions. One of the most prominent form of such interactions is the influx of calcium through store-operated calcium channels that are formed in response to the depletion of ER calcium stores [9, 159-161]. Depletion of the ER calcium stores leads to conformational changes in the stromal intercalation molecules (STIM) protein present on the ER membrane. This in turn induces formation of ER membrane and plasma membrane junctions where the Orai proteins cluster on the plasma membrane and interact with the STIM proteins leading to the formation of active calcium release activated calcium (CRAC) 


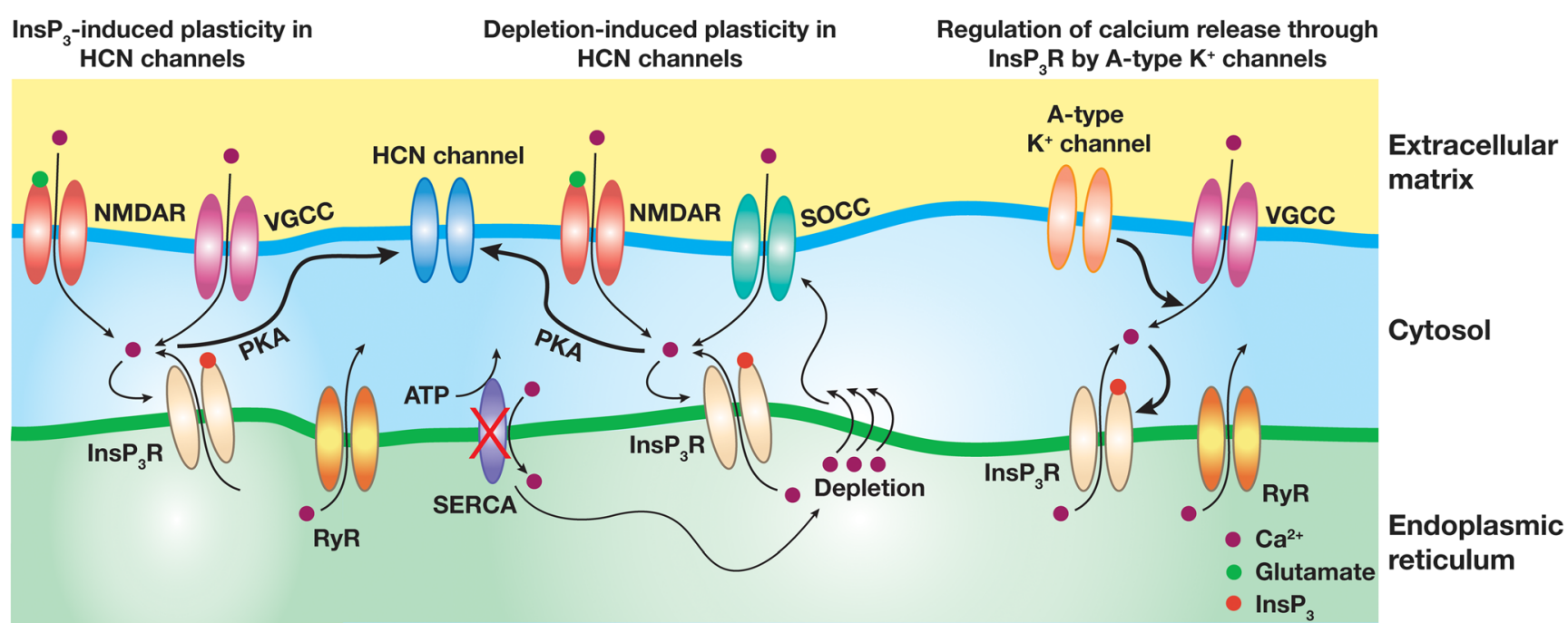

Fig. 1 A diagrammatic representation of the interaction between various VGICs and receptors present on the plasma membrane with the calcium handling mechanisms on the ER membrane. Thick arrows depict the functional interactions between the connecting molecules. Thin arrows point to the flux of calcium ions through various channels and receptors. SERCA, sarcoplasmic endoplasmic reticulum ATP-ase pump; SOCC, store-operated calcium channels; PKA, protein kinase A; RyR, ryanodine receptor. Based on data from $[17,156,158]$

calcium. To elaborate, calcium waves in these models were initiated through an experimentally validated protocol where, increased level of cytosolic $\mathrm{InsP}_{3}$ (corresponding to the bath application of Group1 mGluR agonist) was paired with a short train of APs [16]. When the initial KA conductance was low, the influx of calcium through the VGCCs, during the wave initiation, was high enough to inhibit further release of calcium through the InsP ${ }_{3}$ Rs. As the KA conductance was increased in these neurons, the flux of calcium through the VGCCs dropped to a level where it was optimal to act as the coactivator for the Ins $\mathrm{P}_{3} \mathrm{Rs}$ leading to an increase in the flux of calcium through these receptors. Further increase in the KA conductance led to reduction in this "activator" level of calcium in the cytosol and hence reducing the synergistic action of cytosolic calcium on the $\mathrm{Ins}_{3} \mathrm{Rs}$. This resulted in a decrease in the flux of calcium through the $\operatorname{Ins}_{3} \mathrm{Rs}$, thus giving rise to a bell-shaped dependence of $\operatorname{Ins}_{3} \mathrm{R}$ opening on the KA conductance.

Additionally, analogous to the regulation of EPSPs and backpropagating action potentials by KA channels, the presence of KA conductance also regulated the kinetics of calcium waves in these neuronal models, and manifested as increased latency to peak and enhanced temporal width of the calcium waves $[54,156]$. Notably, this dependence of $\operatorname{InsP}_{3}$ Rs on KA conductance unmasks a novel form of interaction between the ER and the plasma membranes where dendritic excitability can potentially regulate the biochemical signal integration by steering the spatiotemporal spread of calcium. Specifically, as these results demonstrate that the spread of calcium can be critically regulated by interactions between membrane proteins on the plasma membrane and the ER membrane, the spatiotemporal spread of downstream signaling components (that are reliant on calcium as the second messenger) could 
also be altered by such interactions $[149,168-170]$. Therefore, we postulate the presence of voltage-gated channels and their interactions with the ER membrane could steer the activation and spread of biochemical signaling through the relative localization of ion channels on either membrane and that of biochemical signaling components. Interestingly, similar to the results of in vitro slice experiments [115], calcium waves always originated at the branch points in this modeling study also. As several parameters can be independently and precisely controlled in the modeling study, this opened avenues to investigate various morphological, biophysical, and calcium handling mechanisms that could contribute to branch point initiation of calcium waves.

A systematic investigation of various neuronal parameters revealed neuronal morphology, through control of the reaction-diffusion process by regulating the surface area to volume ratio (SVR), to be a critical regulator of wave initiation and propagation in these morphologically elaborate neurons. This modeling study also revealed that changes in Ins $\mathrm{P}_{3} \mathrm{R}$ density regulate the wave amplitude without altering the location of its initiation. To elaborate, high SVR in thin caliber dendrites translates into a large build-up of calcium in these compartments in response to the AP-induced opening of VGCCs. Thus, in the absence of any restorative conductance this initial calcium concentration is high enough to act as an inhibitor for the $\mathrm{InsP}_{3} \mathrm{Rs}$ in oblique dendrites. However, in the presence of KA channels which express in high densities in the oblique dendrites $[54,55,63,171,172]$, the initial calcium influx is reduced to be in the permissive range that can synergistically activate $\mathrm{InsP}_{3} \mathrm{Rs}$ to initiate a calcium wave. The calcium from these compartments can then actively propagate to the main apical dendritic trunk, further amplifying the calcium release at the branch point through CICR. Together, this manifests in the branch point initiation of calcium waves in these neurons, and the expression of KA channels make the stores and $\mathrm{Ins}_{3} \mathrm{R}$ there to be relevant for information processing in obliques (without these channels, the $\mathrm{InsP}_{3} \mathrm{R}$ would just be inhibited by the initial large influx of calcium). These observations suggest that KA channels can regulate both the spatial propagation as well as the temporal aspects of calcium waves, by regulating the dendritic excitability, under various physiological and pathophysiological conditions. Furthermore, the expression of KA channels together with the localized plasticity that these channels can undergo [94, 95] would allow them to regulate the spread of calcium microdomains towards specific subregions in the dendrites.

Apart from KA channels, there are other conductances expressed on the active dendritic membrane such as the hyperpolarization-activated cation non-specific $(\mathrm{HCN})$ channels and the $T$-type calcium channels. In addition to their expression at the soma $[58,59,173]$, these channels are also present in high densities in the neuronal dendrites and regulate the cytosolic calcium concentrations by either directly mediating the influx of calcium ( $T$-type calcium) or indirectly by controlling the dendritic excitability ( $\mathrm{HCN})[3,59,71,120$, 174, 175]. Future experimental and computational lines of investigation are required to delineate the roles of these and other channels in regulating the release of calcium from the ER store and understand the impact of such interactions on the neuronal physiology.

\section{Dynamic Trees and Stores: Plasticity and Cross Regulation Across the Two Active Membranes}

From the description above, it is clear that plasma membrane channels and receptors can regulate ER calcium release through the dependence of ER calcium channels on cytosolic calcium levels and through mechanisms of capacitative calcium entry through store-operated calcium channels (SOCs). Alternately, one can ask whether the release of calcium through the receptors on ER membrane results in reciprocal regulation of receptors and ion channels located on the plasma membrane? Indeed, the release of calcium from the ER stores critically regulates the extent and polarity of several forms of neuronal plasticity through regulation of synaptic receptors $[1$, $10,13,14,20,95,176-178]$. Notably, activation of $\operatorname{InsP}_{3} \mathrm{Rs}$ is necessary for the induction of certain forms of heterosynaptic plasticity, thus highlighting the role of these receptors in regulating neuronal physiology through long-range propagation of calcium signals [20,177].

ER calcium release can also induce plasticity of voltagegated ion channels present on the plasma membrane under various physiological and pathophysiological conditions. As a specific instance of such plasticity, consider disruptions in the calcium homeostasis in the ER, which has been observed as part of several pathological states and has been associated with multiple neurological disorders [1, 179-181]. Experimental imitation of such ER stress response can be achieved by blocking sarcoplasmic endoplasmic calcium ATP-ase (SERCA) pumps that leads to the depletion of ER calcium stores. Such depletion of ER stores results in a decrease in the neuronal excitability and an increase in the optimal response frequency of CA1 pyramidal neurons [17]. This plasticity of the intrinsic response dynamics (IRD) is mediated by an increase in the functional density of HCN channels and associated changes in neuronal biophysical properties [17, 182, 183]. Notably, pharmacological blockade of either the flux of calcium through $\mathrm{InsP}_{3} \mathrm{Rs}$ or SOC channels abolished this form of plasticity suggesting the necessity of $\operatorname{InsP}_{3} \mathrm{R}$ activation for the induction of such plasticity [17]. The role of SOC channels in inducing plasticity of intrinsic neuronal properties is not confined to the hippocampus, but has been shown in other brain regions as well. For instance, the activation of Orai1 has been recently shown to enhance neuronal 
excitability and to reduce the current through KA channels, mediated by the PKC-ERK signaling cascade in dorsal horn neurons [184].

The store depletion-induced plasticity in hippocampal $\mathrm{HCN}$ channels and intrinsic excitability is postulated to serve as a neuroprotective mechanism where reduced excitability can protect the neurons from excitotoxicity in the face of aberrantly high network activity $[17,185]$. More recently, it was demonstrated that depletion of ER stores in vivo through infusion of a SERCA pump inhibitor into the dorsal CA1 region induced anxiogenic-like behaviors, apart from enhancing the current through HCN channels. This was found to be similar to the enhancement of perisomatic HCN1 protein expression and physiological correlates pointing to enhanced HCN channel function, which were observed with chronic unpredictable stress [186]. Together with previous studies on the antidepressant roles of knocking down HCN1 channels from dorsal hippocampus [187], these results point to a critical role for ER calcium stores and their interactions with plasma membrane voltage-gated channels in depressive disorders [186-188].

In another study, designed to assess the sufficiency of $\mathrm{InsP}_{3}$ receptor activation on plasticity of intrinsic neuronal properties, direct infusion of Ins $\mathrm{P}_{3}$ into CA1 pyramidal cells resulted in a similar form of intrinsic plasticity as was observed with ER store depletion [158]. Thus, these sets of experiments established that the activation of $\operatorname{Ins}_{3}$ Rs is both necessary as well as sufficient for the induction of plasticity of $\mathrm{HCN}$ channels expressed on these neurons [17, 158, 182, 186]. Strikingly, the $\mathrm{InsP}_{3}$-induced plasticity is graded, whereby higher activation of $\mathrm{InsP}_{3} \mathrm{Rs}$ resulted in higher amount of plasticity in the IRD measurements. This implies that under physiological conditions, the ER stores induced plasticity of intrinsic properties can express over a wide dynamic range, in a manner that is quantitatively dependent on metabotropic synaptic activity and consequent graded mobilization of cytosolic $\mathrm{InsP}_{3}$. This implies that the magnitude of plasticity in the IRD can be tuned to optimize neuronal response depending on the state of the network activity and represents a cellular mechanism that enables a neuron to maintain its dynamic range of activity by fine tuning its gain over a varied range of network activity (by adjustment of plasma membrane ion channels). In addition to these results pertaining to $\mathrm{HCN}$ channels, in the hippocampal cultured neurons, ER calcium release through RyRs has recently been shown to be necessary to effectuate downregulation of $A$-type potassium channels [189].

Together, it is clear that different signaling cascades differentially recruiting the activation of distinct calcium release channels on the ER membrane can regulate the dendritic excitability by acting on disparate plasma membrane VGICs. It should however be noted that these recent advances reporting such ER-induced plasticity in plasma membrane ion channels, thereby altering the gain and intrinsic response dynamics of neurons, constitute only the tip of the iceberg. There is a large repertoire of receptors and channels present on the plasma membrane which can potentially be regulated by the ER calcium release, locally (the perisomatic plasticity in HCN channels is an example for local regulation) or globally (especially given the spread of the ER across the neuron) with different patterns of release (e.g., tonic vs. phasic with different frequencies and patterns). Given the strong links between ER stores to neuronal physiology and pathophysiology and given the several roles of voltage-gated ion channels in neurophysiology and associated channelopathies in neurological disorders, it is clear that a systematic analysis is required to uncover ER-induced intrinsic plasticity across different cell types to assess the impact of such regulation on neuronal information processing and encoding.

\section{Stores, Waves, and Glue: ER Stores and Calcium Waves in the Glial Syncytium}

Glial cells are cell types that are electrically non-excitable and derive their name from the Greek word for glue as they were first thought to constitute the binding material for the neuron in the brain. Later with the advancement of cellular staining techniques, it became clear that the neuroglia constitute a distinct class of brain cells. Ever since, our understanding about the function of these cells has grown tremendously and it is now evident that they critically participate in regulating information propagation and processing along with metabolism in the brain [21, 190-197].

Astrocytes are a subclass of glia cells which are morphologically complex with cell bodies that appear star-shaped. Due to lack of electrogenic sodium channels [198-200], they were long considered to play a supportive role in the central nervous system where they provide metabolic support and optimize vascular supply to different brain regions. However, in the latter part of the twentieth century, with the advent of calcium imaging techniques, it became clear that astrocytes are calcium excitable, whereby they respond to neuronal activity by increase in their cytosolic calcium levels $[8,21,29,117,118,201]$. Furthermore, calcium imaging along with genetic manipulations of astrocytes have presented compelling lines of evidence that the astrocytes are integral components of information processing in the brain that communicate among themselves (predominantly through gap junctions) as well as with neurons $[21,24,32,33,35,191$, 193, 194, 196]. More recent studies have also uncovered critical roles for astrocytes in the regulation of animal behaviors such as sleep, breathing, mastication, and in the control of circadian rhythm [190, 196, 202-206].

Astrocytes respond to varied sensory stimuli through changes in their calcium signals in vivo [207-209]. Similar calcium signals are also observed upon stimulation of axonal afferents suggesting that astrocytes respond to neuronal 
network activity. Specifically, glial cells respond to the release of neurotransmitters (through activation of metabotropic receptors expressed on their plasma membrane), leading to mobilization of cytosolic $\mathrm{InsP}_{3}$ and subsequent release of calcium from the ER stores. This can induce intracellular calcium waves, which can propagate to neighboring astrocytes through gap junctions to constitute intercellular calcium waves that can travel through the astrocytic syncytium $[11,117,118$, 190, 210, 211]. Astrocytic calcium elevation translates into the release of several neuroactive chemicals from astrocytes - termed gliotransmission - that regulate a myriad of neurophysiological processes including synaptogenesis, synaptic transmission and plasticity, neuronal excitability, action potential propagation, and modulation of neuronal synchrony and behavior [22, 29-31, 34, 203, 212-215].

Individual astrocytes are morphologically elaborate with very fine protoplasmic processes that make close contacts with several neurons and tens of thousands of synapses [8, 123, 196, 216-218]. At synaptic junctions, individual astrocytic processes respond to the neurotransmitters that diffuse around the synaptic cleft. This response is achieved through the activation of high-affinity receptors located on the astrocytic processes, which in turn elicit cytosolic calcium elevation and consequent release of gliotransmitters from the astrocytes. The gliotransmitters act upon various pre- and/or postsynaptic neuronal receptors to modulate synaptic activity, thus making the synaptic information transfer tripartite, where astrocytes are crucial regulators of information transmission and processing [12, 21, 22, 24, 26, 28, 34, 191, 212, 219-221].

\section{Glue, Stores, and Trees: Active Neuronal Dendrites and Gliotransmission}

One of the most direct impacts of gliotransmission on neuronal excitability is the emergence of slow inward currents (SIC) in neighboring neurons. Specifically, glutamate released by the astrocytes can act on the extrasynaptic $N$-methyl-D-aspartate receptors (NMDARs) to elicit SICs in the proximal neurons $[22,31,211,213,222-225]$. Notably, the frequency of SICs is dependent on the extent of astrocytic activation. For instance, synchronous stimulation of Schaffer collaterals in hippocampal slices and consequent excitation of group 1 mGluRs on the astrocytes leads to an increase in the frequency of SICs in CA1 pyramidal neurons [211]. Furthermore, apart from releasing glutamate, astrocytes are capable of releasing various other gliotransmitters that play important roles in the modulation of synaptic transmission and plasticity in various brain regions [21, 22, 206, 226-228].

Although the phenomenon of gliotransmission and its impact on neuronal physiology has been reported to be widespread across different brain regions, the mechanisms behind gliotransmitter release have been debated. It has now emerged that several mechanisms may contribute to gliotransmitter release. For instance, although there is direct evidence for the vesicular release of glutamate in a calcium-dependent manner, non-exocytotic release of glutamate through gap junction hemichannels, swelling activated anion channels, and reverse operation of glutamate transporters have also been reported under different experimental conditions $[8,12,32,124,190$, 222, 229-237]. Additionally, different neurotransmitters can be released through similar molecular machinery. For instance, in the hippocampal astrocytes, bestrophin-1 (BEST1) receptors mediate direct release of glutamate from the astrocytes, whereas in the cerebellar glia, these channels mediate the release of GABA [238, 239].

Adding further complexity to the calcium-mediated gliotransmitter release is the fact that there are diverse mechanisms of cytosolic calcium elevation in astrocytes that may be activated by divergent upstream signaling mechanisms through activation of different plasma membrane bound GPCRs. For example, in hippocampal astrocytes of type 2 Ins $\mathrm{P}_{3} \mathrm{R}$ knockout mice, not all spontaneous calcium signals are abolished suggesting that other sources of calcium (mediated by other receptors and channels) can play a role in the emergence of such signals [123, 218]. Additionally, activation of group-1 mGluRs as well as the protease activated receptor 1 (PAR-1) or $\mathrm{P}_{2 \mathrm{Y} 1}$-purinoreceptors can lead to similar calcium excitability in astrocytes. Whereas pharmacological activation of group-1 mGluR and PAR-1 leads to the gliotransmissioninduced SICs in the proximal neurons, the activation of $\mathrm{P}_{2 \mathrm{Y}^{-}}$ purinoreceptors does not [223].

Astrocytic calcium signaling spans a wide range of spatiotemporal characteristics. Notably, calcium microdomains localized to the fine astrocytic processes that lie in close proximity of the neuronal dendrite can potentially induce localized and heterogeneous neuron-astrocyte interactions $[12,33,123$, $125,217,240,241]$. Specifically, three-dimensional imaging from astrocytic soma and their fine processes has shown calcium activity in these structures to be highly heterogeneous, with different parts of the astrocyte showing significant asynchronous calcium activity [241]. These observations suggest that the dendritic structures that are apposed to different parts of an astrocyte might receive differential localized activation. Yet, much of our understanding about the gliotransmission is based on neuronal somatic recordings, thereby limiting our understanding about the spatial impact of gliotransmission on electrotonically non-compact neuronal structures. Because of the profound impact that gliotransmission has on the neuronal physiology and the fact that nearly $80 \%$ of the total synaptic connections are present on dendrites, it is important to assess the effect of localized gliotransmission on neuronal dendrites. Furthermore, complex spatiokinetic interactions among the VGICs expressed on the neuronal dendrites critically regulate signal integration and processing underlying neuronal physiology $[39,42,43,77,136]$ and can potentially 
regulate the impact of gliotransmission too. Therefore, to understand the emergence and spread of gliotransmissioninduced neuronal events, it is necessary to record these events directly from the dendrites. This can answer whether their impact is limited to specific neuronal compartments, and hence local, or whether they have widespread impact to serve as global modulators of neuronal physiology.

Direct recordings of the voltage counterpart of SICs as slow excitatory potentials (SEPs) from the dendrites of CA1 pyramidal neurons reveal large amplitude voltage deflections in the distal dendritic region [242]. Specifically, the peak amplitude of SEPs in the distal dendrite is about fourfold higher than those recorded at the soma. Additionally, the rise time of spontaneous SEPs (sSEPs) in the distal dendrites ( 200 to $250 \mu \mathrm{m}$ away from the soma) is lower than somatic SEPs. These observations, along with simultaneous somatic and dendritic recording of sSEPs, reveal predominantly dendritic origin of SEPs which are subjected to dendritic filtering as they propagate towards the soma. Notably, the dendritic SEPs could reach amplitudes of tens of millivolts and span hundreds of milliseconds in duration [242]. This is in striking resemblance with the voltage waveform of plateau potentials observed in these neurons under in vivo and in vitro conditions [243-246]. This crucial evidence suggests that gliotransmission can heavily impact dendritic information processing and plasticity by eliciting localized plateau potentials in these neurons.

These direct dendritic recordings of the impact of gliotransmission also revealed that the spatial localization of SEPs is brought about by the active dendritic mechanisms. Specifically, pharmacological blockade of KA and HCN channels - the two prominent VGICs which are heavily expressed on the dendrites of these neurons - uncover two distinct mechanisms for the spatiotemporal localization of SEPs [242]. Blocking KA channels, specifically in the neuron being recorded through intracellular infusion of pharmacological blockers, results in an increase in the amplitude of dendritic but not somatic sSEPs with no significant change in their kinetics and frequency. In contrast, blocking HCN channels, again specifically in the neuron being recorded through intracellular infusion of HCN channel antagonists, does not alter the amplitude of somatic and dendritic sSEPs. However, with blockade of HCN channels there is a significant increase in the rise time, duration, and frequency of dendritic, but not somatic, sSEPs.

Direct dendritic recordings also reveal the SEPs impinge upon the neuronal arbor at much higher frequency than previously estimated by somatic recordings, as several of them were significantly attenuated before they reach the soma due to compartmentalization by active dendritic mechanisms. As mentioned above, the blockade of HCN channels, one such dendritic mechanism involved in active compartmentalization, reveals the higher frequency of SEPs impinging on the neuronal arbor. Mechanistically, blockade of HCN channels increases the intercompartmental coupling [70, 77, 78, 247], thereby resulting in more effective propagation of SEPs towards the dendritic location being recorded [242]. The higher expression of HCN channels in the dendrites therefore translates into a higher impact of their regulation of dendritic SEPs (in comparison to somatic SEPs), together manifesting as an increase in the frequency of dendritic SSEPs when HCN channels are blocked [242].

From the perspective of implications, the localized nature of large amplitude SEPs which are mediated by extrasynaptic NMDARs would translate into local build-up of $\left[\mathrm{Ca}^{2+}\right]_{\mathrm{c}}$ restricted to specific neuronal compartments. Consequently, the ensuing plasticity in the neuronal ion channels and synaptic receptors would also be localized [42, 96, 244-246]. Conversely, spatially restricted plasticity in the VGICs that regulate SEPs $[95,96]$ would translate into local regulation of the spatiotemporal spread of SEPs by the active dendrites. Taken together, active dendritic mechanisms add an additional layer of complexity to neuron-astrocyte interactions. This presents a scenario where gliotransmission, mediated by the astrocytic ER calcium release, can regulate the receptors and ion channels present on the neuronal plasma membrane (Fig. 2), which in turn could regulate ER calcium release in neurons (Fig. 1).

Yet another line of evidence reflecting the intricacies of the complex neuron-astrocyte interactions is exemplified by the fact that the astrocytic ER calcium release can also be triggered by the activation of astrocytic $\mathrm{GABA}_{\mathrm{B}}$ receptors upon release of GABA from interneurons. Consequently, astrocytic glutamate release facilitates glutamatergic synaptic transmission through activation of presynaptic mGluRs the hippocampal microcircuit [248]. Thus, multiple mechanisms of functional interactions between the astrocytic ER stores and neuronal receptors and VGICs heavily impact neuronal information processing in the brain $[196,197]$.

This impact of gliotransmission on behaviorally relevant neuronal computations is further exemplified by the emergence of gliotransmission-induced plateau potentials in CA1 pyramidal neurons [242]. Notably, in vivo patch clamp recordings reveal that during a virtual navigation task, nonplace cell neurons can give rise to place cells subsequent to the occurrence of plateau potentials in successive trials [245]. Furthermore, artificial induction of plateau potentials, by depolarizing current waveforms, can convert a non-place cell into a place cell $[245,246]$, possibly through depolarizationinduced calcium influx which can then induce task-dependent neuronal plasticity. Importantly, this behavioral regime where the emergence of place cells is accompanied by impingement of synchronous synaptic inputs and associated plateau potentials is strikingly similar to the conditions of synaptic activation that results in astrocytic calcium excitability and consequent gliotransmission [211]. Thus, taking all these together, we postulate that the gliotransmission-induced plateau potentials recorded in the hippocampal neurons represent one of the 


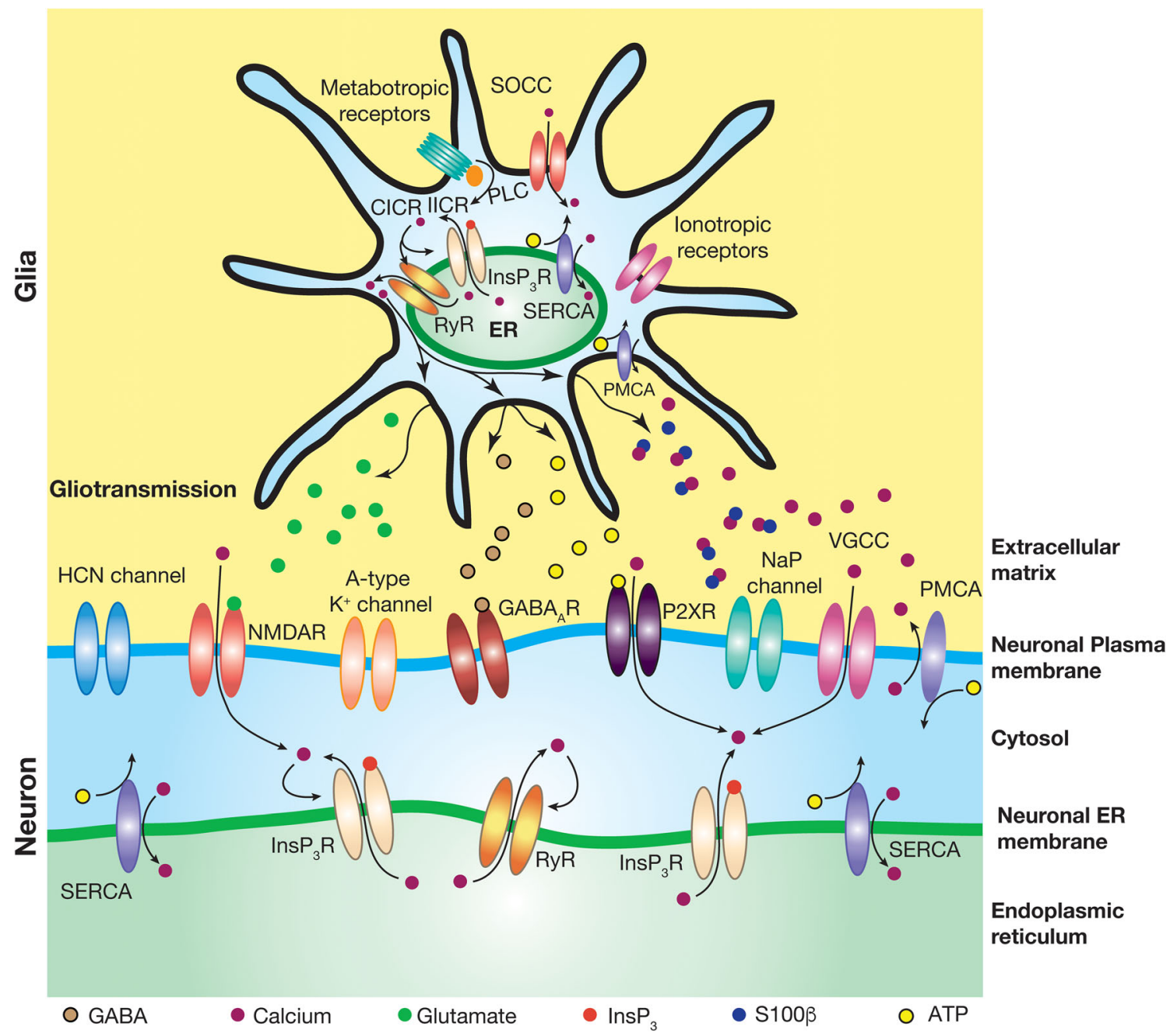

Fig. 2 Multifarious interactions between active glial signaling and active dendritic components. The roles of different gliotransmitters and their neuronal receptors have been studied across various systems and different brain regions. Gliotransmission of different transmitter molecules activate associated receptors on the postsynaptic neuronal membranes. The impact of gliotransmission on dendritic membrane is regulated by the presence of voltage-gated channels (e.g., $\mathrm{HCN}$ and $A$ type potassium) on the dendritic membrane. Glial release of $\mathrm{S} 100 \beta$ reduces extracellular free calcium by binding to them, thereby reducing the suppression (by extracellular free calcium) of persistent sodium (NaP) channels on the neuronal membrane. Pumps and transporters present on the glial and dendritic plasma membranes also contribute to the regulation

cellular mechanisms through which astrocytes could contribute to the emergence of place cells in the hippocampus.

An important form of interaction between astrocytes and ion channels on neuronal plasma membrane is mediated by ions in the extracellular space. Specifically, astrocytes play critical roles in the regulation of ionic homeostasis in the extracellular space, which alter the local reversal potentials of and/or modulate neuronal ion channels, thereby acting as regulators of intrinsic excitability of nearby neurons under various physiological and pathophysiological conditions [125, 249-252]. Recent studies on the trigeminal main sensory of extracellular ionic concentration and homeostasis. Ionotropic and metabotropic receptors on the glia can be activated by neurotransmission and those on neurons can be activated by gliotransmission, forming another form of interaction between glial and dendritic structures. Store-operated calcium channels have been shown to be present on neuronal and glial plasma membranes. IICR, $\mathrm{InsP}_{3}$-induced calcium release; CICR, calcium-induced calcium release; PLC. phospholipase C; SOCC, storeoperated calcium channels; PMCA, plasma membrane calcium extrusion pump; NaP channels, persistent $\mathrm{Na}^{+}$channels; GABA $\mathrm{A}, \gamma-$ aminobutyric acid receptor type $\mathrm{A}$; $\mathrm{P} 2 \mathrm{XR}$, purinergic $\mathrm{P} 2 \mathrm{X}$ receptor; RyR, ryanodine receptor

nucleus [206, 249, 253] have unveiled an additional role for such interactions (Fig. 2) through glial release of S100 $\beta[254$, 255]. Increase in extracellular $\mathrm{S} 100 \beta$, a calcium binding protein, decreases the concentration of extracellular free calcium $\left(\left[\mathrm{Ca}^{2+}\right]_{0}\right)$, which in turn reduces the suppression of persistent sodium channels by $\left[\mathrm{Ca}^{2+}\right]_{\mathrm{o}}[206,249,253,256-259]$. The net effect of glial release of $\mathrm{S} 100 \beta$ is thus a shift in the output mode of the neurons from tonic firing to bursting through augmentation of the persistent sodium current [206, 249, 260, 261]. Recently, persistent sodium channels have been demonstrated to play a critical role in mediating the steep voltage 
dependence of place encoding in hippocampal neurons [262]. In light of this, the contributions of hippocampal glia-neuron interactions, involving extracellular calcium and persistent sodium channels, to spatial encoding should be assessed more carefully. This is especially critical because $\left[\mathrm{Ca}^{2+}\right]_{\mathrm{o}}$ has been demonstrated as a critical regulator of persistent sodium current-dependent burst-firing in hippocampal pyramidal neurons [256].

\section{Dynamic Trees and Glue: Glia-Mediated Plasticity in Neuronal and Synaptic Properties}

Astrocytes critically regulate synaptic transmission and network dynamics through a variety of mechanisms. Functional interactions between astrocytes and neurons sculpt synaptic maturation during the development and set the tone for the basal synaptic transmission in the adult brain [33, 34, 214, 263, 264]. Furthermore, several lines of evidence establish their roles in regulation of short- and long-term synaptic plasticity [35, 196, 214, 265-270].

In spite of a large body of literature exploring roles of glial cells in synaptic plasticity, their roles in the regulation of intrinsic neuronal plasticity has not been investigated. The large amplitude dendritic plateau potentials that are consequent to gliotransmission are mediated by NMDARs [242], thereby resulting in a large calcium influx into the cytosol. From lines of evidence from the active dendritic plasticity literature $[38,43$, $70,89,90,94-97,271,272]$, it is clear that the downstream signaling cascades associated with this calcium elevation is unlikely to be specific for synaptic receptors and are expected to induce plasticity of voltage-gated channel properties as well. As a consequence, an important future direction for astrocyte-neuron interactions is whether gliotransmission can induce plasticity of neuronal intrinsic properties through regulation of active dendritic channels. If they do play such a role in regulating intrinsic dynamics of a neuron, what is the spatial impact of such regulation? Specifically, does glial activity induce localized intrinsic plasticity or is the impact of glia-mediated intrinsic plasticity widespread thereby acting as a global regulator of neuronal computation and output? Answering these questions would require a systematic experimental approach with direct electrophysiological measurements spanning various dendritic and somatic locations. An important consideration while assessing the impact of gliotransmission on neuronal physiology is the observation that there is a common set of transmitter molecules (e.g., glutamate and GABA) that can be released by either neurons or glia. This calls for the experimental strategies where the release of these molecules can be controlled precisely from the glial cells to avoid interpretational ambiguities in their cellular sources. Recent advances in the optogenetic manipulation of astrocytes [273, 274] and chemogenetic strategies, where designer receptors exclusively activated by designer drugs (DREADD) [275] are specifically targeted on the glial cells, could provide reliable solutions towards realization of this objective.

Glial cells are also involved in several other forms of nonsynaptic plasticity in neurons. For instance, myelination of axons by the myelinating oligodendrocyte can undergo activity-dependent changes. Specifically, increase in the performance of cognitive task and learning and memory has been shown to be associated with increased myelination in several model systems. Additionally, axonal myelination is dependent on the electrical activity of the axons where increase in the electrical activity induces more myelination of these axons and vice versa. Additionally, emerging lines of evidence show that myelination is an outcome of elaborate activity-dependent signaling among the perinodal astrocytes, oligodendrocytes, and the axons [276-281]. Any imbalance in such interactions can lead to pathological disorders such as the demyelination disorders that can manifest in several ways. Notably, pathological plasticity and excitotoxicity in the oligodendrocyte is a major cause of demyelination diseases [282, 283]. Finally, pathological plasticity in astrocytes can result in the imbalance of ionic and glutamate homeostasis aggravating epilepsy [284-287] and ischemia associated neuronal death [288-290]. Together, interactions between active glial signaling and signaling cascades that alter active dendritic mechanisms should further expand on this extensive literature, specifically providing direct clues on glial regulation of locationdependent input processing in neurons.

\section{Future Directions: Probing the Breadth and Depth of Subcellular Interactions}

It is now evident that the constituent channels and components present on the ER and the plasma membrane interact in several ways to shape neuronal physiology - many of which have been investigated before and are discussed in this review. In light of these findings, and especially given the abundance and diversity of receptors, ion channels, pumps, and scaffolding molecules expressed on the neuronal membrane, there could be a myriad of ways through which these molecules interact with similar components present on the ER membrane. Thus, the ER membrane-plasma membrane interactions uncovered so far constitute a small subset of a large class of interactions between the two membranes. For instance, apart from the role of KA channels discussed above, several other VGICs could alter the influx of calcium into the cytosol and hence regulate the ER calcium release and consequent spread of calcium waves in the neurons. Some of these channels mediate direct influx of calcium, while others play critical roles in regulating membrane excitability thereby altering the extent of membrane depolarization-induced calcium entry. Given the complex kinetics and voltage-dependent gating profiles of these VGICs that differ significantly from one type to another and 
differences in their expression densities within and across neurons, it is expected that their contribution towards the regulation of ER calcium release would be non-trivial, differential, and variable.

Thus, a systematic analysis of the impact of various VGICs in regulation of emergence and spread of calcium waves is essential to decode this complex network of channels, receptors, and their spatiotemporal extent. For instance, calcium waves can be initiated at specific neuronal compartments (say an oblique dendritic structure) and simultaneous localized pharmacological blockage of various VGICs can shed light on their role(s) in regulating the spatiotemporal spread of calcium waves. Similarly, calcium released from the ER store can activate various downstream signaling pathways which could have varied molecular targets located on the plasma membrane. We have discussed that the flux of calcium through Ins $\mathrm{P}_{3} \mathrm{Rs}$ is both necessary as well as sufficient to induce plasticity of HCN channels present on the plasma membrane. Future studies could explore the casualty of such ER calcium driven signaling pathway in the regulation of other VGICs, receptors, pumps, and other transmembrane and cytosolic proteins and enzymes.

\section{Future Directions: Probing the Breadth and Depth of Glia-Dendrite Interactions}

Neuronal dendrites can release retrograde messengers upon post-synaptic depolarization [291, 292]. Do dendritic SEPs that constitute large dendritic depolarizations also translate into the release of retrograde messengers from the dendrites? How local is such a release, and how do they alter presynaptic neuronal terminals and their release properties? As astrocytic membranes are also endowed with the receptors for endocannabinoid whose activation plays a critical role in regulating synaptic plasticity and gliotransmission [214, 225], would such SEP-activated neuronal retrograde messenger release act as a complex feedback loop that further tightens astrocyte-neuron interactions? Given the diversity of retrograde messengers [291, 292], it is important to investigate if there are differences in the dendritic regulation of astrocytic activity with respect to the retrograde messengers they release. For instance, it would be interesting to ask if such differential release of various retrograde messengers differentially regulates gliotransmission.

What are the neuronal mechanisms that translate into higher impact of gliotransmission in the distal dendritic compartments as evident from the emergence of larger amplitude SEPs at these locations? In the case of synaptic scaling, the higher amplitude of EPSPs in the distal dendrites is attributed to higher densities of AMPA receptors in the dendrites [293-295]. Notably, two different subtypes of extrasynaptic NMDARs mediate SEPs [242]. Is there a density gradient of these receptors that lead to the higher amplitude SEPs in the dendrites? Or is the manifestation of such phenomenon a reflection of higher excitability of distally located astrocytes, thereby resulting in higher gliotransmission there? Addressing these questions is central towards understanding the compartmentalized vs. global nature of astrocyte-neuron interactions. Finally, differences in the dorsoventral population of neurons in the hippocampus in terms of their intrinsic properties, connectivity profiles, and neuronal plasticity are well established [182, 296-302]. Additionally, there are significant differences between superficial and deep pyramidal neurons in terms of afferent inhibition, channel properties, physiological characteristics, and morphology [303-306]. Against this background, it is important to ask whether there are differences in the impact of gliotransmission and neuronastrocyte interactions between the dorsal and the ventral hippocampus and between superficial and deep neurons. Such investigations, involving direct paired astrocytic and somatodendritic recordings along the dorsoventral and deepsuperficial axes would shed further light on nuanced interactions among neurons and astrocytes and reveal the presence of any gradients in such interactions.

\section{Future Directions: Plasticity in Subcellular and Interactional Mechanisms Across Neurons and Glia}

How plastic are the properties of the ER and its receptors? Experimental studies have shown that the morphological organization of the ER store is highly dynamic and exhibits activity-dependent remodeling. For instance, rise in the cytosolic calcium concentration can result in reversible fragmentation of the ER tubules. Additionally, the ER membrane can migrate towards the plasma membrane to form functional SOC channels $[2,159,307]$. Given such structural regulation of the ER membrane, can their receptors and channels, both on astrocytes and neurons, also undergo activity-dependent changes in their density and distribution as a consequence of calcium through the several calcium sources in these structures? If yes, is the nature of such plasticity on the impact of ER mediated signaling spatially localized or widespread throughout the neuron/astrocyte?

Much of our understanding about the functioning of the brain is based on the studies that illustrate the properties and plasticity of neurons. Comparatively speaking, our lack of understanding about the nuances of glial function and especially plasticity is rather astonishing. We know very little about the mechanisms and scope of glial plasticity in the CNS. Although emerging literature has focused on the impact of glia on neuronal synaptic plasticity, whether there are congruent long-term and/or short-term changes in the glial physiology and constitutive components largely remains to be 
explored. Although some studies have reported activitydependent changes in the morphology of astrocytes and microglia but we have very limited understanding about the activity-dependent plasticity of various ion channels, receptors and transporters that critically regulate the physiology of these cells [308-312].

Astrocytic calcium signaling exhibits activity-dependent changes in terms of calcium spatiotemporal dynamics following synaptic activation $[201,313]$. Thus, one can also ask whether changes in the glial calcium signaling is dependent on the amount of calcium present in ER store or on changes to the release machinery therein or on other calcium sources that support calcium elevation within glial cells? In other words, what are the consequences of the depletion of the ER calcium stores on glial physiology and how does it compare with the consequences of the neuronal ER store depletion? Understanding the cellular mechanisms and plasticity rules that govern these changes in the astrocytic function and their interactions with the neuronal plasticity rules would be a big step forward towards our understanding of glial physiology and neuron-glia interactions.

Astrocytes form highly interconnected networks in which they communicate freely with each other via passages of molecules and ions through gap junctions. Thus, they are ideally placed to integrate and regulate the flow of information in the neuron-glial circuit. Thus, one can ask if there are differences in the glial regulation of such information flow in the brain. For instance, is the flow of information in the astrocytic syncytium also plastic and what are the consequences of such plasticity towards information processing and storage in the brain? A recent study revealed input-driven changes in gap junction-dependent coupling in the astrocytic syncytium in the trigeminal main sensory nucleus [253]. There, it was shown that such input-driven changes in gap junctional coupling regulate rhythmic firing in neurons. Future studies could investigate the roles of such input-driven changes in gap junctional coupling in other brain regions, apart from assessing the possibility on whether activity-dependent changes in astrocytic connexin/pannexin density could regulate gliotransmission and astrocyte-dendrite interactions across different brain regions.

The advent of new technologies has continuously advanced our understanding of neuronal and glial physiology. State-of-the-art investigation techniques can be employed to answer some of these outstanding questions regarding glial physiology and plasticity. For instance, with the help of super resolution microscopy $[314,315]$, it is now possible to track the fate of a single molecule over time in live tissues. This can be harnessed to study the expression profiles and changes in the surface expression of various receptors expressed on the glial membrane. Combining this technique with presentation of activity patterns that alter functional and morphological properties of astrocytes can be used to investigate plasticity of receptors, channels, and transporters on the astrocytic membrane. Furthermore optogenetic and chemogenetic activation of astrocytes are being increasingly used for specific activation of glial signaling pathways and provide powerful tools to alter glial activity in vivo [316, 317]. It is an exciting time to study dendrites and glial cells - two structures that were falsely relegated to be passive nutrient suppliers - given the availability of these new techniques and the several unanswered, yet critical questions associated with these two structures and their interactions.

Acknowledgements The authors thank the members of the cellular neurophysiology laboratory for comments on a draft of the manuscript.

Author Contributions SA and RN drafted the manuscript, revised it critically for important intellectual content, and approved the final version of the manuscript.

Funding The work reviewed here was supported by the Wellcome Trust DBT India alliance (through a senior fellowship to RN; IA/S/16/2/ 502727) Human Frontier Science Program (HFSP) Organization (RN), the Department of Biotechnology (RN), the Department of Science and Technology (RN), and the Ministry of Human Resources and Development, India (SA and RN).

\section{Compliance with Ethical Standards}

Conflict of Interest The authors declare that they have no conflict of interest.

Open Access This article is distributed under the terms of the Creative Commons Attribution 4.0 International License (http:// creativecommons.org/licenses/by/4.0/), which permits unrestricted use, distribution, and reproduction in any medium, provided you give appropriate credit to the original author(s) and the source, provide a link to the Creative Commons license, and indicate if changes were made.

\section{References}

1. Verkhratsky A (2005) Physiology and pathophysiology of the calcium store in the endoplasmic reticulum of neurons. Physiol Rev 85(1):201-279. https://doi.org/10.1152/physrev.00004.2004

2. Berridge $\mathrm{MJ}$ (2002) The endoplasmic reticulum: a multifunctional signaling organelle. Cell Calcium 32(5-6):235-249

3. Berridge MJ, Lipp P, Bootman MD (2000) The versatility and universality of calcium signalling. Nat Rev Mol Cell Biol 1(1): 11-21. https://doi.org/10.1038/35036035

4. Berridge MJ (2009) Inositol trisphosphate and calcium signalling mechanisms. Biochim Biophys Acta 1793(6):933-940. https:// doi.org/10.1016/j.bbamcr.2008.10.005

5. Berridge MJ, Irvine RF (1984) Inositol trisphosphate, a novel second messenger in cellular signal transduction. Nature 312(5992):315-321

6. Clapham DE (2007) Calcium signaling. Cell 131(6):1047-1058. https://doi.org/10.1016/j.cell.2007.11.028

7. Foskett JK (2010) Inositol trisphosphate receptor Ca2+ release channels in neurological diseases. Pflugers Arch Eur J Physiol 460(2):481-494. https://doi.org/10.1007/s00424-010-0826-0 
8. Khakh BS, McCarthy KD (2015) Astrocyte calcium signaling: from observations to functions and the challenges therein. Cold Spring Harb Perspect Biol 7(4):a020404. https://doi.org/10.1101/ cshperspect.a020404

9. Lefkimmiatis K, Srikanthan M, Maiellaro I, Moyer MP, Curci S, Hofer AM (2009) Store-operated cyclic AMP signalling mediated by STIM1. Nat Cell Biol 11(4):433-442. https://doi.org/10.1038/ ncb 1850

10. Verkhratsky A (2002) The endoplasmic reticulum and neuronal calcium signalling. Cell Calcium 32(5-6):393-404

11. Verkhratsky A, Kettenmann H (1996) Calcium signalling in glial cells. Trends Neurosci 19(8):346-352

12. Volterra A, Liaudet N, Savtchouk I (2014) Astrocyte Ca(2)(+) signalling: an unexpected complexity. Nat Rev Neurosci 15(5): 327-335. https://doi.org/10.1038/nrn3725

13. Doi T, Kuroda S, Michikawa T, Kawato M (2005) Inositol 1,4,5trisphosphate-dependent $\mathrm{Ca} 2+$ threshold dynamics detect spike timing in cerebellar Purkinje cells. J Neurosci 25(4):950-961. https://doi.org/10.1523/JNEUROSCI.2727-04.2005

14. Emptage NJ, Reid CA, Fine A (2001) Calcium stores in hippocampal synaptic boutons mediate short-term plasticity, storeoperated $\mathrm{Ca} 2+$ entry, and spontaneous transmitter release. Neuron 29(1):197-208

15. Mikoshiba K (2006) Inositol 1,4,5-trisphosphate IP(3) receptors and their role in neuronal cell function. J Neurochem 97(6):16271633. https://doi.org/10.1111/j.1471-4159.2006.03985.x

16. Nakamura T, Barbara JG, Nakamura K, Ross WN (1999) Synergistic release of $\mathrm{Ca} 2+$ from IP3-sensitive stores evoked by synaptic activation of mGluRs paired with backpropagating action potentials. Neuron 24(3):727-737

17. Narayanan R, Dougherty KJ, Johnston D (2010) Calcium store depletion induces persistent Perisomatic increases in the functional density of $\mathrm{h}$ channels in hippocampal pyramidal neurons. Neuron 68(5):921-935. https://doi.org/10.1016/j.neuron.2010.11.033

18. Stutzmann GE, Mattson MP (2011) Endoplasmic reticulum $\mathrm{Ca}(2+$ ) handling in excitable cells in health and disease. Pharmacol Rev 63(3):700-727. https://doi.org/10.1124/pr.110.003814

19. Ross WN (2012) Understanding calcium waves and sparks in central neurons. Nat Rev Neurosci 13(3):157-168. https://doi. org/10.1038/nrn3168

20. Nishiyama M, Hong K, Mikoshiba K, Poo MM, Kato K (2000) Calcium stores regulate the polarity and input specificity of synaptic modification. Nature 408(6812):584-588. https://doi.org/10. 1038/35046067

21. Araque A, Carmignoto G, Haydon PG (2001) Dynamic signaling between astrocytes and neurons. Annu Rev Physiol 63:795-813. https://doi.org/10.1146/annurev.physiol.63.1.795

22. Araque A, Carmignoto G, Haydon PG, Oliet SH, Robitaille R, Volterra A (2014) Gliotransmitters travel in time and space. Neuron 81(4):728-739. https://doi.org/10.1016/j.neuron.2014.02.007

23. Araque A, Parpura V, Sanzgiri RP, Haydon PG (1998) Glutamatedependent astrocyte modulation of synaptic transmission between cultured hippocampal neurons. Eur J Neurosci 10(6):2129-2142

24. Araque A, Parpura V, Sanzgiri RP, Haydon PG (1999) Tripartite synapses: glia, the unacknowledged partner. Trends Neurosci 22(5):208-215

25. Araque A, Sanzgiri RP, Parpura V, Haydon PG (1998) Calcium elevation in astrocytes causes an NMDA receptor-dependent increase in the frequency of miniature synaptic currents in cultured hippocampal neurons. J Neurosci 18(17):6822-6829

26. Halassa MM, Fellin T, Haydon PG (2007) The tripartite synapse: roles for gliotransmission in health and disease. Trends Mol Med 13(2):54-63. https://doi.org/10.1016/j.molmed.2006.12.005

27. Haydon PG (2001) GLIA: listening and talking to the synapse. Nat Rev Neurosci 2(3):185-193. https://doi.org/10.1038/ 35058528
28. Haydon PG, Carmignoto G (2006) Astrocyte control of synaptic transmission and neurovascular coupling. Physiol Rev 86(3): 1009-1031. https://doi.org/10.1152/physrev.00049.2005

29. Parpura V, Basarsky TA, Liu F, Jeftinija K, Jeftinija S, Haydon PG (1994) Glutamate-mediated astrocyte-neuron signalling. Nature 369(6483):744-747. https://doi.org/10.1038/369744a0

30. Min R, Nevian T (2012) Astrocyte signaling controls spike timing-dependent depression at neocortical synapses. Nat Neurosci 15(5):746-753. https://doi.org/10.1038/nn.3075

31. Newman EA, Zahs KR (1998) Modulation of neuronal activity by glial cells in the retina. J Neurosci 18(11):4022-4028

32. Nimmerjahn A (2009) Astrocytes going live: advances and challenges. J Physiol 587(Pt 8):1639-1647. https://doi.org/10.1113/ jphysiol.2008.167171

33. Panatier A, Vallee J, Haber M, Murai KK, Lacaille JC, Robitaille R (2011) Astrocytes are endogenous regulators of basal transmission at central synapses. Cell 146(5):785-798. https://doi.org/10. 1016/j.cell.2011.07.022

34. Pascual O, Casper KB, Kubera C, Zhang J, Revilla-Sanchez R, Sul JY, Takano H, Moss SJ et al (2005) Astrocytic purinergic signaling coordinates synaptic networks. Science 310(5745): 113-116. https://doi.org/10.1126/science. 1116916

35. Perea G, Araque A (2007) Astrocytes potentiate transmitter release at single hippocampal synapses. Science 317(5841):10831086. https://doi.org/10.1126/science. 1144640

36. Halassa MM, Dal Maschio M, Beltramo R, Haydon PG, Benfenati F, Fellin T (2010) Integrated brain circuits: neuron-astrocyte interaction in sleep-related rhythmogenesis. Sci World J 10:1634 1645. https://doi.org/10.1100/tsw.2010.130

37. Yuste R, Tank DW (1996) Dendritic integration in mammalian neurons, a century after Cajal. Neuron 16(4):701-716

38. Johnston D, Narayanan R (2008) Active dendrites: colorful wings of the mysterious butterflies. Trends Neurosci 31(6):309-316. https://doi.org/10.1016/j.tins.2008.03.004

39. Stuart GJ, Spruston N (2015) Dendritic integration: 60 years of progress. Nat Neurosci 18(12):1713-1721. https://doi.org/10. 1038/nn.4157

40. Hausser M, Mel B (2003) Dendrites: bug or feature? Curr Opin Neurobiol 13(3):372-383

41. London M, Hausser M (2005) Dendritic computation. Annu Rev Neurosci 28:503-532

42. Sjostrom PJ, Rancz EA, Roth A, Hausser M (2008) Dendritic excitability and synaptic plasticity. Physiol Rev 88(2):769-840

43. Narayanan R, Johnston D (2012) Functional maps within a single neuron. J Neurophysiol 108(9):2343-2351. https://doi.org/10. 1152/jn.00530.2012

44. Stuart GJ, Dodt HU, Sakmann B (1993) Patch-clamp recordings from the soma and dendrites of neurons in brain slices using infrared video microscopy. Pflugers Arch Eur J Physiol 423(5-6):511-518

45. Stuart GJ, Sakmann B (1994) Active propagation of somatic action potentials into neocortical pyramidal cell dendrites. Nature 367(6458):69-72

46. Jaffe DB, Johnston D, Lasser-Ross N, Lisman JE, Miyakawa H, Ross WN (1992) The spread of Na+ spikes determines the pattern of dendritic $\mathrm{Ca} 2+$ entry into hippocampal neurons. Nature 357(6375):244-246

47. Miyakawa H, Ross WN, Jaffe D, Callaway JC, Lasser-Ross N, Lisman JE, Johnston D (1992) Synaptically activated increases in $\mathrm{Ca} 2+$ concentration in hippocampal CA1 pyramidal cells are primarily due to voltage-gated Ca2+ channels. Neuron 9(6):11631173

48. Ross WN, Manita S (2012) Imaging calcium waves and sparks in central neurons. Cold Spring Harb Protoc 2012(10):1087-1091. https://doi.org/10.1101/pdb.prot071480 
49. Salzberg BM, Davila HV, Cohen LB (1973) Optical recording of impulses in individual neurones of an invertebrate central nervous system. Nature 246(5434):508-509

50. Tsien RY (1980) New calcium indicators and buffers with high selectivity against magnesium and protons: design, synthesis, and properties of prototype structures. Biochemistry 19(11):23962404

51. Yuste R, Denk W (1995) Dendritic spines as basic functional units of neuronal integration. Nature 375(6533):682-684

52. Goldberg JH, Yuste R (2009) Two-photon calcium imaging of spines and dendrites. Cold Spring Harb Protoc 2009(6):pdb prot5231. https://doi.org/10.1101/pdb.prot5231

53. Davie JT, Kole MHP, Letzkus JJ, Rancz EA, Spruston N, Stuart GJ, Häusser M (2006) Dendritic patch-clamp recording. Nat Protoc 1(3): 1235-1247

54. Hoffman DA, Magee JC, Colbert CM, Johnston D (1997) K+ channel regulation of signal propagation in dendrites of hippocampal pyramidal neurons. Nature 387(6636):869-875

55. Kerti K, Lorincz A, Nusser Z (2011) Unique somato-dendritic distribution pattern of Kv4.2 channels on hippocampal CA1 pyramidal cells. Eur J Neurosci 35(1):66-75. https://doi.org/10.1111/ j.1460-9568.2011.07907.x

56. Nusser Z (2012) Differential subcellular distribution of ion channels and the diversity of neuronal function. Curr Opin Neurobiol 22(3):366-371. https://doi.org/10.1016/j.conb.2011.10.006

57. Migliore M, Shepherd GM (2002) Emerging rules for the distributions of active dendritic conductances. Nat Rev Neurosci 3(5): $362-370$

58. Magee JC (1998) Dendritic hyperpolarization-activated currents modify the integrative properties of hippocampal CA1 pyramidal neurons. J Neurosci 18(19):7613-7624

59. Magee JC, Johnston D (1995) Characterization of single voltagegated $\mathrm{Na}+$ and $\mathrm{Ca} 2+$ channels in apical dendrites of rat $\mathrm{CA} 1$ pyramidal neurons. J Physiol 487(Pt 1):67-90

60. Williams SR, Stuart GJ (2000) Backpropagation of physiological spike trains in neocortical pyramidal neurons: implications for temporal coding in dendrites. J Neurosci 20(22):8238-8246

61. Schiller J, Schiller Y, Stuart G, Sakmann B (1997) Calcium action potentials restricted to distal apical dendrites of rat neocortical pyramidal neurons. J Physiol 505(Pt 3):605-616

62. Schiller J, Major G, Koester HJ, Schiller Y (2000) NMDA spikes in basal dendrites of cortical pyramidal neurons. Nature 404(6775):285-289. https://doi.org/10.1038/35005094

63. Losonczy A, Magee JC (2006) Integrative properties of radial oblique dendrites in hippocampal CA1 pyramidal neurons. Neuron 50(2): 291-307. https://doi.org/10.1016/j.neuron.2006.03.016

64. Larkum M (2013) A cellular mechanism for cortical associations: an organizing principle for the cerebral cortex. Trends Neurosci 36(3):141-151. https://doi.org/10.1016/j.tins.2012.11.006

65. Larkum ME, Nevian T, Sandler M, Polsky A, Schiller J (2009) Synaptic integration in tuft dendrites of layer 5 pyramidal neurons: a new unifying principle. Science 325(5941):756-760. https://doi. org/10.1126/science. 1171958

66. Larkum ME, Zhu JJ, Sakmann B (1999) A new cellular mechanism for coupling inputs arriving at different cortical layers. Nature 398(6725):338-341

67. Poirazi P, Brannon T, Mel BW (2003) Arithmetic of subthreshold synaptic summation in a model CA1 pyramidal cell. Neuron 37(6):977-987

68. Poirazi P, Brannon T, Mel BW (2003) Pyramidal neuron as twolayer neural network. Neuron 37(6):989-999

69. Hoffman DA, Johnston D (1999) Neuromodulation of dendritic action potentials. J Neurophysiol 81(1):408-411

70. Narayanan R, Johnston D (2007) Long-term potentiation in rat hippocampal neurons is accompanied by spatially widespread changes in intrinsic oscillatory dynamics and excitability. Neuron 56(6):1061-1075

71. Narayanan R, Johnston D (2010) The h current is a candidate mechanism for regulating the sliding modification threshold in a BCM-like synaptic learning rule. J Neurophysiol 104(2):1020 1033. https://doi.org/10.1152/jn.01129.2009

72. Magee JC (1999) Dendritic Ih normalizes temporal summation in hippocampal CA1 neurons. Nat Neurosci 2(9):848

73. Magee JC (2000) Dendritic integration of excitatory synaptic input. Nat Rev Neurosci 1(3):181-190

74. Williams SR, Stuart GJ (2000) Site independence of EPSP time course is mediated by dendritic $\mathrm{I}(\mathrm{h})$ in neocortical pyramidal neurons. J Neurophysiol 83(5):3177-3182

75. Williams SR, Stuart GJ (2003) Role of dendritic synapse location in the control of action potential output. Trends Neurosci 26(3):147-154

76. Williams SR, Stuart GJ (2003) Voltage- and site-dependent control of the somatic impact of dendritic IPSPs. J Neurosci 23(19):7358-7367

77. Rathour RK, Narayanan R (2012) Influence fields: a quantitative framework for representation and analysis of active dendrites. J Neurophysiol 107(9):2313-2334. https://doi.org/10.1152/jn. 00846.2011

78. Das A, Narayanan R (2014) Active dendrites regulate spectral selectivity in location-dependent spike initiation dynamics of hippocampal model neurons. J Neurosci 34(4):1195-1211. https:// doi.org/10.1523/JNEUROSCI.3203-13.2014

79. Das A, Narayanan R (2015) Active dendrites mediate stratified gamma-range coincidence detection in hippocampal model neurons. J Physiol 593(16):3549-3576. https://doi.org/10.1113/ JP270688

80. Das A, Narayanan R (2017) Theta-frequency selectivity in the somatic spike triggered average of rat hippocampal pyramidal neurons is dependent on HCN channels. J Neurophysiol 118(4): 2251-2266. https://doi.org/10.1152/jn.00356.2017

81. Das A, Rathour RK, Narayanan R (2017) Strings on a violin: location dependence of frequency tuning in active dendrites. Front Cell Neurosci 11:72. https://doi.org/10.3389/fncel.2017. 00072

82. Golding NL, Oertel D (2012) Synaptic integration in dendrites: exceptional need for speed. J Physiol 590(Pt 22):5563-5569. https://doi.org/10.1113/jphysiol.2012.229328

83. Schaefer AT, Larkum ME, Sakmann B, Roth A (2003) Coincidence detection in pyramidal neurons is tuned by their dendritic branching pattern. J Neurophysiol 89(6):3143-3154

84. Softky W (1994) Sub-millisecond coincidence detection in active dendritic trees. Neuroscience 58(1):13-41

85. Stuart GJ, Hausser M (2001) Dendritic coincidence detection of EPSPs and action potentials. Nat Neurosci 4(1):63-71. https://doi. org $/ 10.1038 / 82910$

86. Svoboda K, Denk W, Kleinfeld D, Tank DW (1997) In vivo dendritic calcium dynamics in neocortical pyramidal neurons. Nature 385(6612):161-165. https://doi.org/10.1038/385161a0

87. Wang SS, Denk W, Hausser M (2000) Coincidence detection in single dendritic spines mediated by calcium release. Nat Neurosci 3(12):1266-1273. https://doi.org/10.1038/81792

88. Sinha M, Narayanan R (2015) HCN channels enhance spike phase coherence and regulate the phase of spikes and LFPs in the thetafrequency range. Proc Natl Acad Sci U S A 112(17):E2207E2216. https://doi.org/10.1073/pnas.1419017112

89. Remy S, Beck H, Yaari Y (2010) Plasticity of voltage-gated ion channels in pyramidal cell dendrites. Curr Opin Neurobiol 20: 503-509. https://doi.org/10.1016/j.conb.2010.06.006

90. Narayanan R, Johnston D (2008) The h channel mediates location dependence and plasticity of intrinsic phase response in rat hippocampal neurons. J Neurosci 28(22):5846-5860

91. Johnston D, Christie BR, Frick A, Gray R, Hoffman DA, Schexnayder LK, Watanabe S, Yuan LL (2003) Active dendrites, 
potassium channels and synaptic plasticity. Philos Trans R Soc Lond Ser B Biol Sci 358(1432):667-674. https://doi.org/10. 1098/rstb.2002.1248

92. Johnston D, Hoffman DA, Magee JC, Poolos NP, Watanabe S, Colbert CM, Migliore M (2000) Dendritic potassium channels in hippocampal pyramidal neurons. J Physiol 525(Pt 1):75-81

93. Johnston D, Magee JC, Colbert CM, Cristie BR (1996) Active properties of neuronal dendrites. Annu Rev Neurosci 19:165186. https://doi.org/10.1146/annurev.ne.19.030196.001121

94. Frick A, Johnston D (2005) Plasticity of dendritic excitability. J Neurobiol 64(1):100-115

95. Frick A, Magee J, Johnston D (2004) LTP is accompanied by an enhanced local excitability of pyramidal neuron dendrites. Nat Neurosci 7(2):126-135

96. Losonczy A, Makara JK, Magee JC (2008) Compartmentalized dendritic plasticity and input feature storage in neurons. Nature 452(7186):436-441

97. Shah MM, Hammond RS, Hoffman DA (2010) Dendritic ion channel trafficking and plasticity. Trends Neurosci 33(7):307316. https://doi.org/10.1016/j.tins.2010.03.002

98. Terasaki M, Slater NT, Fein A, Schmidek A, Reese TS (1994) Continuous network of endoplasmic reticulum in cerebellar Purkinje neurons. Proc Natl Acad Sci U S A 91(16):7510-7514

99. Golovina VA, Blaustein MP (2000) Unloading and refilling of two classes of spatially resolved endoplasmic reticulum $\mathrm{Ca}(2+)$ stores in astrocytes. Glia 31(1):15-28

100. LaFerla FM (2002) Calcium dyshomeostasis and intracellular signalling in Alzheimer's disease. Nat Rev Neurosci 3(11):862-872. https://doi.org/10.1038/nrn960

101. Solovyova N, Verkhratsky A (2002) Monitoring of free calcium in the neuronal endoplasmic reticulum: an overview of modern approaches. J Neurosci Methods 122(1):1-12

102. Holtzclaw LA, Pandhit S, Bare DJ, Mignery GA, Russell JT (2002) Astrocytes in adult rat brain express type 2 inositol 1,4,5trisphosphate receptors. Glia 39(1):69-84. https://doi.org/10. 1002/glia.10085

103. Golovina VA, Blaustein MP (1997) Spatially and functionally distinct $\mathrm{Ca} 2+$ stores in sarcoplasmic and endoplasmic reticulum. Science 275(5306):1643-1648

104. Hertle DN, Yeckel MF (2007) Distribution of inositol-1,4,5-trisphosphate receptor isotypes and ryanodine receptor isotypes during maturation of the rat hippocampus. Neuroscience 150(3):625638. https://doi.org/10.1016/j.neuroscience.2007.09.058

105. Choe CU, Ehrlich BE (2006) The inositol 1,4,5-trisphosphate receptor (IP3R) and its regulators: sometimes good and sometimes bad teamwork. Sci STKE 2006(363):re15. https://doi.org/10. 1126/stke.3632006re15

106. Sharp AH, McPherson PS, Dawson TM, Aoki C, Campbell KP, Snyder SH (1993) Differential immunohistochemical localization of inositol 1,4,5-trisphosphate- and ryanodine-sensitive Ca2+ release channels in rat brain. J Neurosci 13(7):3051-3063

107. Bezprozvanny I, Watras J, Ehrlich BE (1991) Bell-shaped calcium-response curves of Ins(1,4,5)P3- and calcium-gated channels from endoplasmic reticulum of cerebellum. Nature 351(6329): 751-754. https://doi.org/10.1038/351751a0

108. Taylor CW, Tovey SC (2010) IP(3) receptors: toward understanding their activation. Cold Spring Harb Perspect Biol 2(12): a004010. https://doi.org/10.1101/cshperspect.a004010

109. Fill M, Copello JA (2002) Ryanodine receptor calcium release channels. Physiol Rev 82(4):893-922. https://doi.org/10.1152/ physrev.00013.2002

110. Tu H, Wang Z, Bezprozvanny I (2005) Modulation of mammalian inositol 1,4,5-trisphosphate receptor isoforms by calcium: a role of calcium sensor region. Biophys J 88(2):1056-1069. https://doi. org/10.1529/biophysj.104.049601
111. Foskett JK, White C, Cheung KH, Mak DO (2007) Inositol trisphosphate receptor $\mathrm{Ca} 2+$ release channels. Physiol Rev 87(2): 593-658. https://doi.org/10.1152/physrev.00035.2006

112. Hagar RE, Burgstahler AD, Nathanson MH, Ehrlich BE (1998) Type III InsP3 receptor channel stays open in the presence of increased calcium. Nature 396(6706):81-84. https://doi.org/10. $1038 / 23954$

113. Boehning D, Patterson RL, Sedaghat L, Glebova NO, Kurosaki T, Snyder SH (2003) Cytochrome c binds to inositol $(1,4,5)$ trisphosphate receptors, amplifying calcium-dependent apoptosis. Nat Cell Biol 5(12):1051-1061. https://doi.org/10.1038/ncb1063

114. Miyazaki K, Ross WN (2013) Ca2+ sparks and puffs are generated and interact in rat hippocampal CA1 pyramidal neuron dendrites. J Neurosci 33(45):17777-17788. https://doi.org/10.1523/ JNEUROSCI.2735-13.2013

115. Nakamura T, Lasser-Ross N, Nakamura K, Ross WN (2002) Spatial segregation and interaction of calcium signalling mechanisms in rat hippocampal CA1 pyramidal neurons. J Physiol 543(Pt 2):465-480

116. Nakamura T, Nakamura K, Lasser-Ross N, Barbara JG, Sandler VM, Ross WN (2000) Inositol 1,4,5-trisphosphate (IP3)-mediated $\mathrm{Ca} 2+$ release evoked by metabotropic agonists and backpropagating action potentials in hippocampal CA1 pyramidal neurons. J Neurosci 20(22):8365-8376

117. Cornell-Bell AH, Finkbeiner SM, Cooper MS, Smith SJ (1990) Glutamate induces calcium waves in cultured astrocytes: longrange glial signaling. Science 247(4941):470-473

118. Dani JW, Chernjavsky A, Smith SJ (1992) Neuronal activity triggers calcium waves in hippocampal astrocyte networks. Neuron 8(3):429-440

119. Hirase H, Qian L, Bartho P, Buzsaki G (2004) Calcium dynamics of cortical astrocytic networks in vivo. PLoS Biol 2(4):E96. https://doi.org/10.1371/journal.pbio.0020096

120. Berridge MJ (1998) Neuronal calcium signaling. Neuron 21(1): 13-26

121. Berridge MJ, Irvine RF (1989) Inositol phosphates and cell signalling. Nature 341(6239):197-205. https://doi.org/10.1038/ $341197 \mathrm{a} 0$

122. Major G, Larkum ME, Schiller J (2013) Active properties of neocortical pyramidal neuron dendrites. Annu Rev Neurosci 36:1-24. https://doi.org/10.1146/annurev-neuro-062111-150343

123. Khakh BS, Sofroniew MV (2015) Diversity of astrocyte functions and phenotypes in neural circuits. Nat Neurosci 18(7):942-952. https://doi.org/10.1038/nn.4043

124. Malarkey EB, Parpura V (2008) Mechanisms of glutamate release from astrocytes. Neurochem Int 52(1-2):142-154. https://doi.org/ 10.1016/j.neuint.2007.06.005

125. Bazargani N, Attwell D (2016) Astrocyte calcium signaling: the third wave. Nat Neurosci 19(2):182-189. https://doi.org/10.1038/ nn. 4201

126. Pyapali GK, Sik A, Penttonen M, Buzsaki G, Turner DA (1998) Dendritic properties of hippocampal CA1 pyramidal neurons in the rat: intracellular staining in vivo and in vitro. J Comp Neurol 391(3):335-352. https://doi.org/10.1002/(SICI)10969861(19980216)391:3<335::AID-CNE4>3.0.CO;2-2

127. Amaral DG, Witter MP (1989) The three-dimensional organization of the hippocampal formation: a review of anatomical data. Neuroscience 31(3):571-591

128. Larkman A, Mason A (1990) Correlations between morphology and electrophysiology of pyramidal neurons in slices of rat visual cortex. I. Establishment of cell classes. J Neurosci 10(5):1407-1414

129. Andersen P, Morris R, Amaral D, Bliss T, O'Keefe J (2006) The hippocampus book. Oxford University Press, New York

130. Nusser Z (2009) Variability in the subcellular distribution of ion channels increases neuronal diversity. Trends Neurosci 32(5):267274. https://doi.org/10.1016/j.tins.2009.01.003 
131. Lev-Ram V, Miyakawa H, Lasser-Ross N, Ross WN (1992) Calcium transients in cerebellar Purkinje neurons evoked by intracellular stimulation. J Neurophysiol 68(4):1167-1177

132. Zador A, Koch C (1994) Linearized models of calcium dynamics: formal equivalence to the cable equation. J Neurosci 14(8):47054715

133. Rall W (1977) Core conductor theory and cable properties of neurons. In: Kandel ER (ed) Handbook of physiology. The nervous system, Cellular biology of neurons, vol 1. American Physiological Society, Bethesda, pp. 39-97

134. Johnston D, Wu SM (1995) Foundations of cellular neurophysiology. The MIT Press, Cambridge

135. Kim S, Guzman SJ, Hu H, Jonas P (2012) Active dendrites support efficient initiation of dendritic spikes in hippocampal CA3 pyramidal neurons. Nat Neurosci 15(4):600-606. https://doi.org/ $10.1038 / \mathrm{nn} .3060$

136. Spruston N (2008) Pyramidal neurons: dendritic structure and synaptic integration. Nat Rev Neurosci 9(3):206-221. https://doi. org/10.1038/nrn2286

137. Magee JC (1999) Dendritic lh normalizes temporal summation in hippocampal CA1 neurons. Nat Neurosci 2(6):508-514

138. Rall W (1962) Theory of physiological properties of dendrites. Ann N Y Acad Sci 96:1071-1092

139. Rall W (1962) Electrophysiology of a dendritic neuron model. Biophys J 2(2 Pt 2):145-167

140. Magee JC, Johnston D (1995) Synaptic activation of voltage-gated channels in the dendrites of hippocampal pyramidal neurons. Science 268(5208):301-304

141. Hodgkin AL, Huxley AF (1952) A quantitative description of membrane current and its application to conduction and excitation in nerve. J Physiol 117(4):500-544

142. Hille B (2001) Ion channels of excitable membranes, Third edn. Sinauer Associates, Inc, Sunderland

143. Bezanilla F, Armstrong CM (1972) Negative conductance caused by entry of sodium and cesium ions into the potassium channels of squid axons. J Gen Physiol 60(5):588-608

144. Bezanilla F, Armstrong CM (1977) Inactivation of the sodium channel. I. Sodium current experiments. J Gen Physiol 70(5): 549-566

145. Aldrich RW, Corey DP, Stevens CF (1983) A reinterpretation of mammalian sodium channel gating based on single channel recording. Nature 306(5942):436-441

146. Berridge MJ (2006) Calcium microdomains: organization and function. Cell Calcium 40(5-6):405-412. https://doi.org/10. 1016/j.ceca.2006.09.002

147. Sabatini BL, Oertner TG, Svoboda K (2002) The life cycle of $\mathrm{Ca}(2+)$ ions in dendritic spines. Neuron 33(3):439-452

148. Augustine GJ, Santamaria F, Tanaka K (2003) Local calcium signaling in neurons. Neuron 40(2):331-346

149. Rizzuto R, Pozzan T (2006) Microdomains of intracellular Ca2+: molecular determinants and functional consequences. Physiol Rev 86(1):369-408. https://doi.org/10.1152/physrev.00004.2005

150. Power JM, Sah P (2008) Competition between calcium-activated $\mathrm{K}+$ channels determines cholinergic action on firing properties of basolateral amygdala projection neurons. J Neurosci 28(12): 3209-3220. https://doi.org/10.1523/JNEUROSCI.4310-07.2008

151. Larkum ME, Watanabe S, Nakamura T, Lasser-Ross N, Ross WN (2003) Synaptically activated Ca2+ waves in layer 2/3 and layer 5 rat neocortical pyramidal neurons. J Physiol 549(Pt 2):471-488. https://doi.org/10.1113/jphysiol.2002.037614

152. Hagenston AM, Fitzpatrick JS, Yeckel MF (2008) MGluRmediated calcium waves that invade the soma regulate firing in layer V medial prefrontal cortical pyramidal neurons. Cereb Cortex 18(2):407-423. https://doi.org/10.1093/cercor/bhm075

153. Watanabe S, Hong M, Lasser-Ross N, Ross WN (2006) Modulation of calcium wave propagation in the dendrites and to the soma of rat hippocampal pyramidal neurons. J Physiol 575(Pt 2):455-468. https://doi.org/10.1113/jphysiol.2006.114231

154. Zhou S, Ross WN (2002) Threshold conditions for synaptically evoking $\mathrm{Ca}(2+)$ waves in hippocampal pyramidal neurons. J Neurophysiol 87(4):1799-1804. https://doi.org/10.1152/jn. 00601.2001

155. Jaffe DB, Brown TH (1994) Metabotropic glutamate receptor activation induces calcium waves within hippocampal dendrites. J Neurophysiol 72(1):471-474

156. Ashhad S, Narayanan R (2013) Quantitative interactions between the A-type $\mathrm{K}+$ current and inositol trisphosphate receptors regulate intraneuronal Ca2 + waves and synaptic plasticity. J Physiol 591(Pt 7):1645-1669. https://doi.org/10.1113/jphysiol.2012.245688

157. Dent MA, Raisman G, Lai FA (1996) Expression of type 1 inositol 1,4,5-trisphosphate receptor during axogenesis and synaptic contact in the central and peripheral nervous system of developing rat. Development 122(3):1029-1039

158. Ashhad S, Johnston D, Narayanan R (2015) Activation of InsP(3) receptors is sufficient for inducing graded intrinsic plasticity in rat hippocampal pyramidal neurons. J Neurophysiol 113(7):20022013. https://doi.org/10.1152/jn.00833.2014

159. Lewis RS (2011) Store-operated calcium channels: new perspectives on mechanism and function. Cold Spring Harb Perspect Biol 3(12). https://doi.org/10.1101/cshperspect.a003970

160. Prakriya M, Feske S, Gwack Y, Srikanth S, Rao A, Hogan PG (2006) Orail is an essential pore subunit of the CRAC channel. Nature 443(7108):230-233. https://doi.org/10.1038/nature05122

161. Vig M, Peinelt C, Beck A, Koomoa DL, Rabah D, KoblanHuberson M, Kraft S, Turner H et al (2006) CRACM1 is a plasma membrane protein essential for store-operated $\mathrm{Ca} 2+$ entry. Science 312(5777):1220-1223. https://doi.org/10.1126/science.1127883

162. Park CY, Shcheglovitov A, Dolmetsch R (2010) The CRAC channel activator STIM1 binds and inhibits L-type voltage-gated calcium channels. Science 330(6000):101-105. https://doi.org/10. 1126/science. 1191027

163. Wang Y, Deng X, Mancarella S, Hendron E, Eguchi S, Soboloff J, Tang XD, Gill DL (2010) The calcium store sensor, STIM1, reciprocally controls Orai and CaV1.2 channels. Science 330(6000): 105-109. https://doi.org/10.1126/science.1191086

164. Budde T, Meuth S, Pape HC (2002) Calcium-dependent inactivation of neuronal calcium channels. Nat Rev Neurosci 3(11):873883. https://doi.org/10.1038/nrn959

165. El-Hassar L, Hagenston AM, D'Angelo LB, Yeckel MF (2011) Metabotropic glutamate receptors regulate hippocampal CA1 pyramidal neuron excitability via $\mathrm{Ca}(2+)$ wave-dependent activation of SK and TRPC channels. J Physiol 589(Pt 13):3211-3229. https://doi.org/10.1113/jphysiol.2011.209783

166. Adelman JP, Maylie J, Sah P (2012) Small-conductance Ca2+activated K+ channels: form and function. Annu Rev Physiol 74:245-269. https://doi.org/10.1146/annurev-physiol-020911153336

167. Weaver AK, Olsen ML, McFerrin MB, Sontheimer H (2007) BK channels are linked to inositol 1,4,5-triphosphate receptors via lipid rafts: a novel mechanism for coupling $[\mathrm{Ca}(2+)](\mathrm{i})$ to ion channel activation. J Biol Chem 282(43):31558-31568. https:// doi.org/10.1074/jbc.M702866200

168. Neves SR, Iyengar R (2002) Modeling of signaling networks. Bioessays 24(12):1110-1117. https://doi.org/10.1002/bies.1154

169. Neves SR, Iyengar R (2009) Models of spatially restricted biochemical reaction systems. J Biol Chem 284(9):5445-5449. https://doi.org/10.1074/jbc.R800058200

170. Neves SR, Tsokas P, Sarkar A, Grace EA, Rangamani P, Taubenfeld SM, Alberini CM, Schaff JC et al (2008) Cell shape and negative links in regulatory motifs together control spatial information flow in signaling networks. Cell 133(4):666-680. https://doi.org/10.1016/j.cell.2008.04.025 
171. Frick A, Magee J, Koester HJ, Migliore M, Johnston D (2003) Normalization of $\mathrm{Ca} 2+$ signals by small oblique dendrites of CA1 pyramidal neurons. J Neurosci 23(8):3243-3250

172. Gasparini S, Losonczy A, Chen X, Johnston D, Magee JC (2007) Associative pairing enhances action potential back-propagation in radial oblique branches of CA1 pyramidal neurons. J Physiol 580(Pt.3):787-800. https://doi.org/10.1113/jphysiol.2006.121343

173. Lorincz A, Notomi T, Tamas G, Shigemoto R, Nusser Z (2002) Polarized and compartment-dependent distribution of HCN1 in pyramidal cell dendrites. Nat Neurosci 5(11):1185-1193

174. Catterall WA (2011) Voltage-gated calcium channels. Cold Spring Harb Perspect Biol 3(8):a003947. https://doi.org/10.1101/ cshperspect.a003947

175. Tsien RW, Lipscombe D, Madison DV, Bley KR, Fox AP (1988) Multiple types of neuronal calcium channels and their selective modulation. Trends Neurosci 11(10):431-438

176. Caporale N, Dan Y (2008) Spike timing-dependent plasticity: a Hebbian learning rule. Annu Rev Neurosci 31:25-46. https://doi. org/10.1146/annurev.neuro.31.060407.125639

177. Dudman JT, Tsay D, Siegelbaum SA (2007) A role for synaptic inputs at distal dendrites: instructive signals for hippocampal longterm plasticity. Neuron 56(5):866-879. https://doi.org/10.1016/j. neuron.2007.10.020

178. Nevian T, Sakmann B (2006) Spine Ca2+ signaling in spiketiming-dependent plasticity. J Neurosci 26(43):11001-11013. https://doi.org/10.1523/JNEUROSCI.1749-06.2006

179. Marciniak SJ, Ron D (2006) Endoplasmic reticulum stress signaling in disease. Physiol Rev 86(4):1133-1149. https://doi.org/10. 1152/physrev.00015.2006

180. Mattson MP, LaFerla FM, Chan SL, Leissring MA, Shepel PN, Geiger JD (2000) Calcium signaling in the ER: its role in neuronal plasticity and neurodegenerative disorders. Trends Neurosci 23(5):222-229

181. Paschen W, Mengesdorf T (2005) Endoplasmic reticulum stress response and neurodegeneration. Cell Calcium 38(3-4):409-415. https://doi.org/10.1016/j.ceca.2005.06.019

182. Clemens AM, Johnston D (2014) Age- and location-dependent differences in store depletion-induced h-channel plasticity in hippocampal pyramidal neurons. J Neurophysiol 111(6):1369-1382. https://doi.org/10.1152/jn.00839.2013

183. Brager DH, Lewis AS, Chetkovich DM, Johnston D (2013) Shortand long-term plasticity in CA1 neurons from mice lacking hchannel auxiliary subunit TRIP8b. J Neurophysiol 110(10): 2350-2357. https://doi.org/10.1152/jn.00218.2013

184. Dou Y, Xia J, Gao R, Gao X, Munoz FM, Wei D, Tian Y, Barrett JE et al (2018) Orail plays a crucial role in central sensitization by modulating neuronal excitability. J Neurosci 38(4):887-900. https://doi.org/10.1523/JNEUROSCI.3007-17.2017

185. Schmidt S, Ehrlich BE (2010) Unloading intracellular calcium stores reveals regionally specific functions. Neuron 68(5):806808. https://doi.org/10.1016/j.neuron.2010.11.039

186. Kim CS, Brager DH, Johnston D (2017) Perisomatic changes in hchannels regulate depressive behaviors following chronic unpredictable stress. Mol Psychiatry 23:892-903. https://doi.org/10. 1038/mp.2017.28

187. Kim CS, Chang PY, Johnston D (2012) Enhancement of dorsal hippocampal activity by knockdown of HCN1 channels leads to anxiolytic- and antidepressant-like behaviors. Neuron 75(3):503516. https://doi.org/10.1016/j.neuron.2012.05.027

188. Shah MM (2012) HCN1 channels: a new therapeutic target for depressive disorders? Sci Signal 5(244):pe44. https://doi.org/10. 1126/scisignal.2003593

189. Yang YS, Jeon SC, Kang MS, Kim SH, Eun SY, Jin SH, Jung SC (2017) Activation of ryanodine receptors is required for PKAmediated downregulation of A-type $\mathrm{K}+$ channels in rat hippocampal neurons. J Neurosci Res 95:2469-2482. https://doi. org/10.1002/jnr.24076

190. Zorec R, Araque A, Carmignoto G, Haydon PG, Verkhratsky A, Parpura V (2012) Astroglial excitability and gliotransmission: an appraisal of $\mathrm{Ca} 2+$ as a signalling route. ASN Neuro 4(2): AN20110061. https://doi.org/10.1042/AN20110061

191. Volterra A, Meldolesi J (2005) Astrocytes, from brain glue to communication elements: the revolution continues. Nat Rev Neurosci 6(8):626-640. https://doi.org/10.1038/nrn1722

192. Allen NJ, Barres BA (2009) Neuroscience: glia - more than just brain glue. Nature 457(7230):675-677. https://doi.org/10.1038/ $457675 \mathrm{a}$

193. Nedergaard M, Ransom B, Goldman SA (2003) New roles for astrocytes: redefining the functional architecture of the brain. Trends Neurosci 26(10):523-530. https://doi.org/10.1016/j.tins. 2003.08.008

194. Ransom B, Behar T, Nedergaard M (2003) New roles for astrocytes (stars at last). Trends Neurosci 26(10):520-522. https://doi. org/10.1016/j.tins.2003.08.006

195. Anderson CM, Nedergaard M (2003) Astrocyte-mediated control of cerebral microcirculation. Trends Neurosci 26(7):340-344; author reply 344-345. https://doi.org/10.1016/S0166-2236(03) 00141-3

196. Halassa MM, Haydon PG (2010) Integrated brain circuits: astrocytic networks modulate neuronal activity and behavior. Annu Rev Physiol 72:335-355. https://doi.org/10.1146/annurevphysiol-021909-135843

197. Pannasch U, Rouach N (2013) Emerging role for astroglial networks in information processing: from synapse to behavior. Trends Neurosci 36(7):405-417. https://doi.org/10.1016/j.tins. 2013.04.004

198. Sontheimer H, Waxman SG (1993) Expression of voltageactivated ion channels by astrocytes and oligodendrocytes in the hippocampal slice. J Neurophysiol 70(5):1863-1873

199. Zhou M, Schools GP, Kimelberg HK (2006) Development of GLAST(+) astrocytes and NG2(+) glia in rat hippocampus CA1: mature astrocytes are electrophysiologically passive. J Neurophysiol 95(1):134-143. https://doi.org/10.1152/jn.00570. 2005

200. Pappalardo LW, Black JA, Waxman SG (2016) Sodium channels in astroglia and microglia. Glia 64(10):1628-1645. https://doi.org/ 10.1002/glia.22967

201. Pasti L, Volterra A, Pozzan T, Carmignoto G (1997) Intracellular calcium oscillations in astrocytes: a highly plastic, bidirectional form of communication between neurons and astrocytes in situ. J Neurosci 17(20):7817-7830

202. Halassa MM, Florian C, Fellin T, Munoz JR, Lee SY, Abel T, Haydon PG, Frank MG (2009) Astrocytic modulation of sleep homeostasis and cognitive consequences of sleep loss. Neuron 61(2):213-219. https://doi.org/10.1016/j.neuron.2008.11.024

203. Gourine AV, Kasymov V, Marina N, Tang F, Figueiredo MF, Lane S, Teschemacher AG, Spyer KM et al (2010) Astrocytes control breathing through $\mathrm{pH}$-dependent release of ATP. Science 329(5991):571-575. https://doi.org/10.1126/science.1190721

204. Brancaccio M, Patton AP, Chesham JE, Maywood ES, Hastings MH (2017) Astrocytes control circadian timekeeping in the suprachiasmatic nucleus via glutamatergic signaling. Neuron 93(6): 1420-1435 e1425. https://doi.org/10.1016/j.neuron.2017.02.030

205. Forsberg D, Ringstedt T, Herlenius E (2017) Astrocytes release prostaglandin E2 to modify respiratory network activity. eLife 6 . https://doi.org/10.7554/eLife.29566

206. Morquette P, Verdier D, Kadala A, Fethiere J, Philippe AG, Robitaille R, Kolta A (2015) An astrocyte-dependent mechanism for neuronal rhythmogenesis. Nat Neurosci 18(6):844-854. https://doi.org/10.1038/nn.4013 
207. Schummers J, Yu H, Sur M (2008) Tuned responses of astrocytes and their influence on hemodynamic signals in the visual cortex. Science 320(5883):1638-1643. https://doi.org/10.1126/science. 1156120

208. Sawinski J, Wallace DJ, Greenberg DS, Grossmann S, Denk W, Kerr JN (2009) Visually evoked activity in cortical cells imaged in freely moving animals. Proc Natl Acad Sci U S A 106(46):1955719562. https://doi.org/10.1073/pnas.0903680106

209. Lind BL, Brazhe AR, Jessen SB, Tan FC, Lauritzen MJ (2013) Rapid stimulus-evoked astrocyte $\mathrm{Ca} 2+$ elevations and hemodynamic responses in mouse somatosensory cortex in vivo. Proc Natl Acad Sci U S A 110(48):E4678-E4687. https://doi.org/10. 1073/pnas. 1310065110

210. Porter JT, McCarthy KD (1996) Hippocampal astrocytes in situ respond to glutamate released from synaptic terminals. J Neurosci 16(16):5073-5081

211. Fellin T, Pascual O, Gobbo S, Pozzan T, Haydon PG, Carmignoto G (2004) Neuronal synchrony mediated by astrocytic glutamate through activation of extrasynaptic NMDA receptors. Neuron 43(5):729-743. https://doi.org/10.1016/j.neuron.2004.08.011

212. Kang J, Jiang L, Goldman SA, Nedergaard M (1998) Astrocytemediated potentiation of inhibitory synaptic transmission. Nat Neurosci 1(8):683-692. https://doi.org/10.1038/3684

213. Parri HR, Gould TM, Crunelli V (2001) Spontaneous astrocytic $\mathrm{Ca} 2+$ oscillations in situ drive NMDAR-mediated neuronal excitation. Nat Neurosci 4(8):803-812. https://doi.org/10.1038/90507

214. Navarrete M, Araque A (2010) Endocannabinoids potentiate synaptic transmission through stimulation of astrocytes. Neuron 68(1):113-126. https://doi.org/10.1016/j.neuron.2010.08.043

215. Han J, Kesner P, Metna-Laurent M, Duan T, Xu L, Georges F, Koehl M, Abrous DN et al (2012) Acute cannabinoids impair working memory through astroglial CB1 receptor modulation of hippocampal LTD. Cell 148(5):1039-1050. https://doi.org/10. 1016/j.cell.2012.01.037

216. Bushong EA, Martone ME, Jones YZ, Ellisman MH (2002) Protoplasmic astrocytes in CA1 stratum radiatum occupy separate anatomical domains. J Neurosci 22(1):183-192

217. Ogata K, Kosaka T (2002) Structural and quantitative analysis of astrocytes in the mouse hippocampus. Neuroscience 113(1):221-233

218. Srinivasan R, Huang BS, Venugopal S, Johnston AD, Chai H, Zeng H, Golshani P, Khakh BS (2015) Ca(2+) signaling in astrocytes from Ip3r2(-/-) mice in brain slices and during startle responses in vivo. Nat Neurosci 18(5):708-717. https://doi.org/10. 1038/nn.4001

219. Perea G, Navarrete M, Araque A (2009) Tripartite synapses: astrocytes process and control synaptic information. Trends Neurosci 32(8):421-431. https://doi.org/10.1016/j.tins.2009.05.001

220. Halassa MM, Fellin T, Takano H, Dong JH, Haydon PG (2007) Synaptic islands defined by the territory of a single astrocyte. J Neurosci 27(24):6473-6477. https://doi.org/10.1523/ JNEUROSCI.1419-07.2007

221. Postnov DE, Koreshkov RN, Brazhe NA, Brazhe AR, Sosnovtseva OV (2009) Dynamical patterns of calcium signaling in a functional model of neuron-astrocyte networks. J Biol Phys 35(4):425-445. https://doi.org/10.1007/s10867-009-9156-x

222. Kang N, Xu J, Xu Q, Nedergaard M, Kang J (2005) Astrocytic glutamate release-induced transient depolarization and epileptiform discharges in hippocampal CA1 pyramidal neurons. J Neurophysiol 94(6):4121-4130. https://doi.org/10.1152/jn. 00448.2005

223. Shigetomi E, Bowser DN, Sofroniew MV, Khakh BS (2008) Two forms of astrocyte calcium excitability have distinct effects on NMDA receptor-mediated slow inward currents in pyramidal neurons. J Neurosci 28(26):6659-6663. https://doi.org/10.1523/ JNEUROSCI.1717-08.2008
224. Reyes-Haro D, Muller J, Boresch M, Pivneva T, Benedetti B, Scheller A, Nolte C, Kettenmann H (2010) Neuron-astrocyte interactions in the medial nucleus of the trapezoid body. J Gen Physiol 135(6):583-594. https://doi.org/10.1085/jgp.200910354

225. Navarrete M, Araque A (2008) Endocannabinoids mediate neuron-astrocyte communication. Neuron 57(6):883-893. https://doi.org/10.1016/j.neuron.2008.01.029

226. Mothet JP, Pollegioni L, Ouanounou G, Martineau M, Fossier P, Baux G (2005) Glutamate receptor activation triggers a calciumdependent and SNARE protein-dependent release of the gliotransmitter D-serine. Proc Natl Acad Sci U S A 102(15): 5606-5611. https://doi.org/10.1073/pnas.0408483102

227. Butt AM (2011) ATP: a ubiquitous gliotransmitter integrating neuron-glial networks. Semin Cell Dev Biol 22(2):205-213. https://doi.org/10.1016/j.semcdb.2011.02.023

228. Panatier A, Theodosis DT, Mothet JP, Touquet B, Pollegioni L, Poulain DA, Oliet SH (2006) Glia-derived D-serine controls NMDA receptor activity and synaptic memory. Cell 125(4):775784. https://doi.org/10.1016/j.cell.2006.02.051

229. Hamilton NB, Attwell D (2010) Do astrocytes really exocytose neurotransmitters? Nat Rev Neurosci 11(4):227-238. https://doi. org $/ 10.1038 / \mathrm{nrn} 2803$

230. Fiacco TA, Agulhon C, McCarthy KD (2009) Sorting out astrocyte physiology from pharmacology. Annu Rev Pharmacol Toxicol 49:151-174. https://doi.org/10.1146/annurev.pharmtox. 011008.145602

231. Smith K (2010) Neuroscience: settling the great glia debate. Nature 468(7321):160-162. https://doi.org/10.1038/468160a

232. Parpura V, Zorec R (2010) Gliotransmission: exocytotic release from astrocytes. Brain Res Rev 63(1-2):83-92. https://doi.org/ 10.1016/j.brainresrev.2009.11.008

233. Warr O, Takahashi M, Attwell D (1999) Modulation of extracellular glutamate concentration in rat brain slices by cystineglutamate exchange. J Physiol 514(Pt 3):783-793

234. Nicholls D, Attwell D (1990) The release and uptake of excitatory amino acids. Trends Pharmacol Sci 11(11):462-468

235. Duan S, Anderson CM, Keung EC, Chen Y, Chen Y, Swanson RA (2003) P2X7 receptor-mediated release of excitatory amino acids from astrocytes. J Neurosci 23(4):1320-1328

236. Duan S, Anderson CM, Stein BA, Swanson RA (1999) Glutamate induces rapid upregulation of astrocyte glutamate transport and cellsurface expression of GLAST. J Neurosci 19(23):10193-10200

237. Szatkowski M, Barbour B, Attwell D (1990) Non-vesicular release of glutamate from glial cells by reversed electrogenic glutamate uptake. Nature 348(6300):443-446. https://doi.org/10.1038/ $348443 \mathrm{a} 0$

238. Lee S, Yoon BE, Berglund K, Oh SJ, Park H, Shin HS, Augustine GJ, Lee CJ (2010) Channel-mediated tonic GABA release from glia. Science 330(6005):790-796. https://doi.org/10.1126/science. 1184334

239. Woo DH, Han KS, Shim JW, Yoon BE, Kim E, Bae JY, Oh SJ, Hwang EM et al (2012) TREK-1 and Best1 channels mediate fast and slow glutamate release in astrocytes upon GPCR activation. Cell 151(1):25-40. https://doi.org/10.1016/j.cell.2012.09.005

240. Srinivasan R, Lu TY, Chai H, Xu J, Huang BS, Golshani P, Coppola G, Khakh BS (2016) New transgenic mouse lines for selectively targeting astrocytes and studying calcium signals in astrocyte processes in situ and in vivo. Neuron 92(6):11811195. https://doi.org/10.1016/j.neuron.2016.11.030

241. Bindocci E, Savtchouk I, Liaudet N, Becker D, Carriero G, Volterra A (2017) Three-dimensional $\mathrm{Ca}(2+)$ imaging advances understanding of astrocyte biology. Science 356(6339):eaai8185. https://doi.org/10.1126/science.aai8185

242. Ashhad S, Narayanan R (2016) Active dendrites regulate the impact of gliotransmission on rat hippocampal pyramidal neurons. 
Proc Natl Acad Sci U S A 113(23):E3280-E3289. https://doi.org/ $10.1073 /$ pnas. 1522180113

243. Suzuki T, Kodama S, Hoshino C, Izumi T, Miyakawa H (2008) A plateau potential mediated by the activation of extrasynaptic NMDA receptors in rat hippocampal CA1 pyramidal neurons. Eur J Neurosci 28(3):521-534. https://doi.org/10.1111/j.14609568.2008.06324.x

244. Takahashi H, Magee JC (2009) Pathway interactions and synaptic plasticity in the dendritic tuft regions of CA1 pyramidal neurons. Neuron 62(1):102-111. https://doi.org/10.1016/j.neuron.2009.03.007

245. Bittner KC, Grienberger C, Vaidya SP, Milstein AD, Macklin JJ, Suh J, Tonegawa S, Magee JC (2015) Conjunctive input processing drives feature selectivity in hippocampal CA1 neurons. Nat Neurosci 18(8):1133-1142. https://doi.org/10.1038/nn.4062

246. Bittner KC, Milstein AD, Grienberger C, Romani S, Magee JC (2017) Behavioral time scale synaptic plasticity underlies CA1 place fields. Science 357(6355):1033-1036. https://doi.org/10. 1126/science.aan3846

247. Hu H, Vervaeke K, Graham LJ, Storm JF (2009) Complementary theta resonance filtering by two spatially segregated mechanisms in CA1 hippocampal pyramidal neurons. J Neurosci 29(46):1447214483. https://doi.org/10.1523/JNEUROSCI.0187-09.2009

248. Perea G, Gomez R, Mederos S, Covelo A, Ballesteros JJ, Schlosser L, Hernandez-Vivanco A, Martin-Fernandez M et al (2016) Activity-dependent switch of GABAergic inhibition into glutamatergic excitation in astrocyte-neuron networks. eLife 5. https://doi.org/10.7554/eLife.20362

249. Kadala A, Verdier D, Morquette P, Kolta A (2015) Ion homeostasis in rhythmogenesis: the interplay between neurons and astroglia. Physiology 30(5):371-388. https://doi.org/10.1152/ physiol.00023.2014

250. Xu L, Zeng LH, Wong M (2009) Impaired astrocytic gap junction coupling and potassium buffering in a mouse model of tuberous sclerosis complex. Neurobiol Dis 34(2):291-299

251. Wang F, Smith NA, Xu Q, Fujita T, Baba A, Matsuda T, Takano T, Bekar L et al (2012) Astrocytes modulate neural network activity by $\mathrm{Ca}(2)+-d e p e n d e n t$ uptake of extracellular K+. Sci Signal 5(218):ra26. https://doi.org/10.1126/scisignal.2002334

252. Torres A, Wang F, Xu Q, Fujita T, Dobrowolski R, Willecke K, Takano T, Nedergaard M (2012) Extracellular Ca(2)(+) acts as a mediator of communication from neurons to glia. Sci Signal 5(208):ra8. https://doi.org/10.1126/scisignal.2002160

253. Condamine S, Lavoie R, Verdier D, Kolta A (2018) Functional rhythmogenic domains defined by astrocytic networks in the trigeminal main sensory nucleus. Glia 66(2):311-326. https://doi. org/10.1002/glia.23244

254. Ciccarelli R, Di Iorio P, Bruno V, Battaglia G, D'Alimonte I, D'Onofrio M, Nicoletti F, Caciagli F (1999) Activation of A(1) adenosine or mGlu3 metabotropic glutamate receptors enhances the release of nerve growth factor and S-100beta protein from cultured astrocytes. Glia 27(3):275-281

255. Sakatani S, Seto-Ohshima A, Shinohara Y, Yamamoto Y, Yamamoto H, Itohara S, Hirase H (2008) Neural-activitydependent release of S100B from astrocytes enhances kainateinduced gamma oscillations in vivo. J Neurosci 28(43):1092810936. https://doi.org/10.1523/JNEUROSCI.3693-08.2008

256. Su H, Alroy G, Kirson ED, Yaari Y (2001) Extracellular calcium modulates persistent sodium current-dependent burst-firing in hippocampal pyramidal neurons. J Neurosci 21(12):4173-4182

257. Li Z, Hatton GI (1996) Oscillatory bursting of phasically firing rat supraoptic neurones in low-Ca2+ medium: $\mathrm{Na}+$ influx, cytosolic Ca2+ and gap junctions. J Physiol 496(Pt 2):379-394

258. Brocard F, Shevtsova NA, Bouhadfane M, Tazerart S, Heinemann U, Rybak IA, Vinay L (2013) Activity-dependent changes in extracellular $\mathrm{Ca} 2+$ and $\mathrm{K}+$ reveal pacemakers in the spinal locomotor-related network. Neuron 77(6):1047-1054. https://doi. org/10.1016/j.neuron.2013.01.026

259. Tazerart S, Vinay L, Brocard F (2008) The persistent sodium current generates pacemaker activities in the central pattern generator for locomotion and regulates the locomotor rhythm. J Neurosci 28(34):8577-8589. https://doi.org/10.1523/JNEUROSCI.143708.2008

260. Davey GE, Murmann P, Heizmann CW (2001) Intracellular Ca2+ and $\mathrm{Zn} 2+$ levels regulate the alternative cell density-dependent secretion of S100B in human glioblastoma cells. J Biol Chem 276(33):30819-30826. https://doi.org/10.1074/jbc.M103541200

261. Lasic E, Galland F, Vardjan N, Sribar J, Krizaj I, Leite MC, Zorec R, Stenovec M (2016) Time-dependent uptake and trafficking of vesicles capturing extracellular S100B in cultured rat astrocytes. J Neurochem 139(2):309-323. https://doi.org/10.1111/jnc.13754

262. Hsu CL, Zhao X, Milstein AD, Spruston N (2018) Persistent sodium current mediates the steep voltage dependence of spatial coding in hippocampal pyramidal neurons. Neuron. https://doi. org/10.1016/j.neuron.2018.05.025

263. Lee CJ, Mannaioni G, Yuan H, Woo DH, Gingrich MB, Traynelis SF (2007) Astrocytic control of synaptic NMDA receptors. J Physiol 581(Pt 3):1057-1081. https://doi.org/10.1113/jphysiol. 2007.130377

264. Martin R, Bajo-Graneras R, Moratalla R, Perea G, Araque A (2015) Circuit-specific signaling in astrocyte-neuron networks in basal ganglia pathways. Science 349(6249):730-734. https://doi. org/10.1126/science.aaa7945

265. Perea G, Araque A (2010) GLIA modulates synaptic transmission. Brain Res Rev 63(1-2):93-102. https://doi.org/10.1016/j. brainresrev.2009.10.005

266. Suzuki A, Stern SA, Bozdagi O, Huntley GW, Walker RH, Magistretti PJ, Alberini CM (2011) Astrocyte-neuron lactate transport is required for long-term memory formation. Cell 144(5):810-823. https://doi.org/10.1016/j.cell.2011.02.018

267. Sibille J, Pannasch U, Rouach N (2014) Astroglial potassium clearance contributes to short-term plasticity of synaptically evoked currents at the tripartite synapse. J Physiol 592(1):87102. https://doi.org/10.1113/jphysiol.2013.261735

268. Beattie EC, Stellwagen D, Morishita W, Bresnahan JC, Ha BK, Von Zastrow M, Beattie MS, Malenka RC (2002) Control of synaptic strength by glial TNFalpha. Science 295(5563):2282-2285. https://doi.org/10.1126/science.1067859

269. Pannasch U, Vargova L, Reingruber J, Ezan P, Holcman D, Giaume C, Sykova E, Rouach N (2011) Astroglial networks scale synaptic activity and plasticity. Proc Natl Acad Sci U S A 108(20): 8467-8472. https://doi.org/10.1073/pnas.1016650108

270. Chen J, Tan Z, Zeng L, Zhang X, He Y, Gao W, Wu X, Li Y et al (2013) Heterosynaptic long-term depression mediated by ATP released from astrocytes. Glia 61(2):178-191. https://doi.org/10. 1002/glia.22425

271. Magee JC, Johnston D (2005) Plasticity of dendritic function. Curr Opin Neurobiol 15(3):334-342. https://doi.org/10.1016/j.conb. 2005.05.013

272. Shah MM (2014) Cortical HCN channels: function, trafficking and plasticity. J Physiol 592:2711-2719. https://doi.org/10.1113/ jphysiol.2013.270058

273. Ji ZG, Wang H (2015) Optogenetic control of astrocytes: is it possible to treat astrocyte-related epilepsy? Brain Res Bull 110: 20-25. https://doi.org/10.1016/j.brainresbull.2014.10.013

274. Poskanzer KE, Yuste R (2016) Astrocytes regulate cortical state switching in vivo. Proc Natl Acad Sci U S A 113(19):E2675E2684. https://doi.org/10.1073/pnas.1520759113

275. Roth BL (2016) DREADDs for neuroscientists. Neuron 89(4): 683-694. https://doi.org/10.1016/j.neuron.2016.01.040 
276. Fields RD (2015) A new mechanism of nervous system plasticity: activity-dependent myelination. Nat Rev Neurosci 16(12):756767. https://doi.org/10.1038/nrn4023

277. Fields RD (2008) White matter in learning, cognition and psychiatric disorders. Trends Neurosci 31(7):361-370. https://doi.org/ 10.1016/j.tins.2008.04.001

278. Demerens C, Stankoff B, Logak M, Anglade P, Allinquant B, Couraud F, Zalc B, Lubetzki C (1996) Induction of myelination in the central nervous system by electrical activity. Proc Natl Acad Sci U S A 93(18):9887-9892

279. Ishibashi T, Dakin KA, Stevens B, Lee PR, Kozlov SV, Stewart CL, Fields RD (2006) Astrocytes promote myelination in response to electrical impulses. Neuron 49(6):823-832. https://doi.org/10. 1016/j.neuron.2006.02.006

280. Gibson EM, Purger D, Mount CW, Goldstein AK, Lin GL, Wood LS, Inema I, Miller SE et al (2014) Neuronal activity promotes oligodendrogenesis and adaptive myelination in the mammalian brain. Science 344(6183):1252304. https://doi.org/10.1126/ science. 1252304

281. Stevens B, Porta S, Haak LL, Gallo V, Fields RD (2002) Adenosine: a neuron-glial transmitter promoting myelination in the CNS in response to action potentials. Neuron 36(5):855-868

282. Miller RH, Mi S (2007) Dissecting demyelination. Nat Neurosci 10(11):1351-1354. https://doi.org/10.1038/nn1995

283. Matute C, Alberdi E, Domercq M, Perez-Cerda F, Perez-Samartin A, Sanchez-Gomez MV (2001) The link between excitotoxic oligodendroglial death and demyelinating diseases. Trends Neurosci 24(4):224-230

284. Tian GF, Azmi H, Takano T, Xu Q, Peng W, Lin J, Oberheim N, Lou N et al (2005) An astrocytic basis of epilepsy. Nat Med 11(9): 973-981. https://doi.org/10.1038/nm1277

285. Hinterkeuser S, Schroder W, Hager G, Seifert G, Blumcke I, Elger CE, Schramm J, Steinhauser C (2000) Astrocytes in the hippocampus of patients with temporal lobe epilepsy display changes in potassium conductances. Eur J Neurosci 12(6):2087-2096

286. Coulter DA, Eid T (2012) Astrocytic regulation of glutamate homeostasis in epilepsy. Glia 60(8):1215-1226. https://doi.org/10. 1002/glia.22341

287. Das A, Wallace GC, Holmes C, McDowell ML, Smith JA, Marshall JD, Bonilha L, Edwards JC et al (2012) Hippocampal tissue of patients with refractory temporal lobe epilepsy is associated with astrocyte activation, inflammation, and altered expression of channels and receptors. Neuroscience 220:237-246. https://doi.org/10.1016/j.neuroscience.2012.06.002

288. Swanson RA, Ying W, Kauppinen TM (2004) Astrocyte influences on ischemic neuronal death. Curr Mol Med 4(2):193-205

289. Panickar KS, Norenberg MD (2005) Astrocytes in cerebral ischemic injury: morphological and general considerations. Glia 50(4): 287-298. https://doi.org/10.1002/glia.20181

290. Takano T, Oberheim N, Cotrina ML, Nedergaard M (2009) Astrocytes and ischemic injury. Stroke 40(3 Suppl):S8-S12. https://doi.org/10.1161/STROKEAHA.108.533166

291. Ludwig M, Pittman QJ (2003) Talking back: dendritic neurotransmitter release. Trends Neurosci 26(5):255-261. https://doi.org/10. 1016/S0166-2236(03)00072-9

292. Regehr WG, Carey MR, Best AR (2009) Activity-dependent regulation of synapses by retrograde messengers. Neuron 63(2):154 170. https://doi.org/10.1016/j.neuron.2009.06.021

293. Magee JC, Cook EP (2000) Somatic EPSP amplitude is independent of synapse location in hippocampal pyramidal neurons. Nat Neurosci 3(9):895-903

294. Smith MA, Ellis-Davies GC, Magee JC (2003) Mechanism of the distance-dependent scaling of Schaffer collateral synapses in rat CA1 pyramidal neurons. J Physiol 548(Pt 1):245-258
295. Andrasfalvy BK, Magee JC (2001) Distance-dependent increase in AMPA receptor number in the dendrites of adult hippocampal CA1 pyramidal neurons. J Neurosci 21(23):9151-9159

296. Honigsperger C, Marosi M, Murphy R, Storm JF (2015) Dorsoventral differences in Kv7/M-current and its impact on resonance, temporal summation and excitability in rat hippocampal pyramidal cells. J Physiol 593(7):1551-1580. https://doi.org/10. 1113/jphysiol.2014.280826

297. Marcelin B, Liu Z, Chen Y, Lewis AS, Becker A, McClelland S, Chetkovich DM, Migliore M et al (2012) Dorsoventral differences in intrinsic properties in developing CA1 pyramidal cells. J Neurosci 32(11):3736-3747. https://doi.org/10.1523/JNEUROSCI.5870-11. 2012

298. Malik R, Johnston D (2017) Dendritic GIRK channels gate the integration window, plateau potentials, and induction of synaptic plasticity in dorsal but not ventral CA1 neurons. J Neurosci 37(14):3940-3955. https://doi.org/10.1523/JNEUROSCI.278416.2017

299. Fanselow MS, Dong HW (2010) Are the dorsal and ventral hippocampus functionally distinct structures? Neuron 65(1):7-19. https://doi.org/10.1016/j.neuron.2009.11.031

300. Grigoryan G, Korkotian E, Segal M (2012) Selective facilitation of LTP in the ventral hippocampus by calcium stores. Hippocampus 22(7):1635-1644. https://doi.org/10.1002/hipo. 22000

301. Dougherty KA, Islam T, Johnston D (2012) Intrinsic excitability of CA1 pyramidal neurones from the rat dorsal and ventral hippocampus. J Physiol 590(Pt 22):5707-5722. https://doi.org/10.1113/ jphysiol.2012.242693

302. Dougherty KA, Nicholson DA, Diaz L, Buss EW, Neuman KM, Chetkovich DM, Johnston D (2013) Differential expression of $\mathrm{HCN}$ subunits alters voltage-dependent gating of h-channels in CA1 pyramidal neurons from dorsal and ventral hippocampus. J Neurophysiol 109(7):1940-1953. https://doi.org/10.1152/jn. 00010.2013

303. Danielson NB, Zaremba JD, Kaifosh P, Bowler J, Ladow M, Losonczy A (2016) Sublayer-specific coding dynamics during spatial navigation and learning in hippocampal area CA1. Neuron 91(3):652-665. https://doi.org/10.1016/j.neuron.2016. 06.020

304. Maroso M, Szabo GG, Kim HK, Alexander A, Bui AD, Lee SH, Lutz B, Soltesz I (2016) Cannabinoid control of learning and memory through HCN channels. Neuron 89(5):1059-1073. https://doi.org/10.1016/j.neuron.2016.01.023

305. Mizuseki K, Diba K, Pastalkova E, Buzsaki G (2011) Hippocampal CA1 pyramidal cells form functionally distinct sublayers. Nat Neurosci 14(9):1174-1181. https://doi.org/10. 1038/nn.2894

306. Valero M, Cid E, Averkin RG, Aguilar J, Sanchez-Aguilera A, Viney TJ, Gomez-Dominguez D, Bellistri E et al (2015) Determinants of different deep and superficial CA1 pyramidal cell dynamics during sharp-wave ripples. Nat Neurosci 18(9):12811290. https://doi.org/10.1038/nn.4074

307. Subramanian K, Meyer T (1997) Calcium-induced restructuring of nuclear envelope and endoplasmic reticulum calcium stores. Cell 89(6):963-971

308. Shao Y, McCarthy KD (1994) Plasticity of astrocytes. Glia 11(2): 147-155. https://doi.org/10.1002/glia.440110209

309. Shao Y, Enkvist MO, McCarthy KD (1994) Glutamate blocks astroglial stellation: effect of glutamate uptake and volume changes. Glia 11(1):1-10. https://doi.org/10.1002/glia.440110103

310. Bobak JB, Salm AK (1996) Plasticity of astrocytes of the ventral glial limitans subjacent to the supraoptic nucleus. J Comp Neurol 376(2):188-197. https://doi.org/10.1002/(SICI)10969861(19961209)376:2\&1t;188::AID-CNE2\&gt;3.0.CO;2-\# 
311. Genoud C, Quairiaux C, Steiner P, Hirling H, Welker E, Knott GW (2006) Plasticity of astrocytic coverage and glutamate transporter expression in adult mouse cortex. PLoS Biol 4(11):e343. https:// doi.org/10.1371/journal.pbio.0040343

312. Witcher MR, Kirov SA, Harris KM (2007) Plasticity of perisynaptic astroglia during synaptogenesis in the mature rat hippocampus. Glia 55(1):13-23. https://doi.org/10.1002/glia.20415

313. Perea G, Araque A (2005) Properties of synaptically evoked astrocyte calcium signal reveal synaptic information processing by astrocytes. J Neurosci 25(9):2192-2203. https://doi.org/10.1523/ JNEUROSCI.3965-04.2005

314. Betzig E, Patterson GH, Sougrat R, Lindwasser OW, Olenych S, Bonifacino JS, Davidson MW, Lippincott-Schwartz J et al (2006) Imaging intracellular fluorescent proteins at nanometer resolution.
Science 313(5793):1642-1645. https://doi.org/10.1126/science. 1127344

315. Rust MJ, Bates M, Zhuang X (2006) Sub-diffraction-limit imaging by stochastic optical reconstruction microscopy (STORM). Nat Methods 3(10):793-795. https://doi.org/10.1038/nmeth929

316. Li D, Agulhon C, Schmidt E, Oheim M, Ropert N (2013) New tools for investigating astrocyte-to-neuron communication. Front Cell Neurosci 7:193. https://doi.org/10.3389/fncel.2013.00193

317. Adamsky A, Kol A, Kreisel T, Doron A, Ozeri-Engelhard N, Melcer T, Refaeli R, Horn H et al (2018) Astrocytic activation generates de novo neuronal potentiation and memory enhancement. Cell 174(1):59-71 e14. https://doi.org/10.1016/j.cell.2018. 05.002 